$$
\begin{aligned}
& \text { النملذجة السببية للعلاقات بين العوامل الخمسة الكبرى للشخصية والكفاءة الذاتية والسّعادة } \\
& \text { للى طلبة جامعة العلوم والتكنولوجيا الأردنية } \\
& \text { ور ابعة الدبابي } \\
& \text { وكالة الغوث الدو لية، الأردن }
\end{aligned}
$$

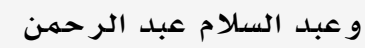

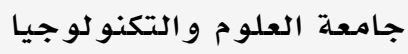

$$
\begin{aligned}
& \text { *لدون الدبابي } \\
& \text { الأر دنية، الأردن } \\
& \text { جامعة الإمام عبد الرجمن } \\
& \text { بن فيصل، السعودية }
\end{aligned}
$$

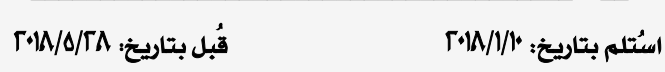

ملخص: هدفت هذه الدّر اسلة إلى الكشف عن العلاقات السببيّة بين العوامل الخمسة الكبرى للشخصية والكفاءة

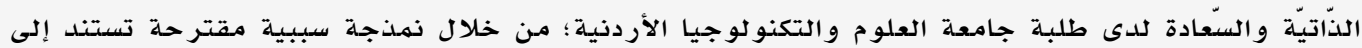

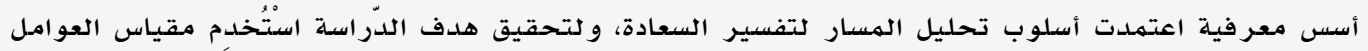

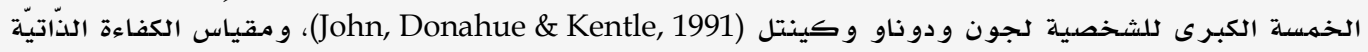

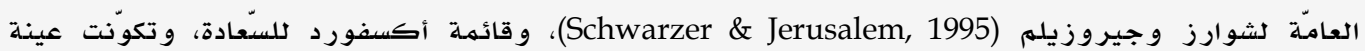

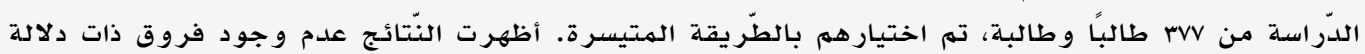

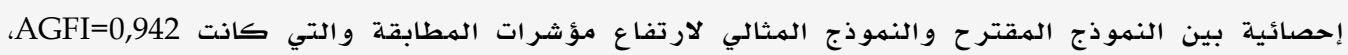

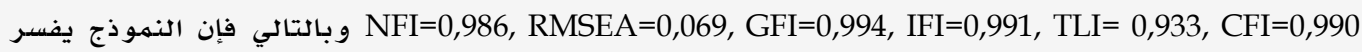
العلاقات التي تم اقتر احها وهو يعبر عن النهوذج السببي الأمثل لمتغيرات الدراسة. كلمات مفتاحية: العوامل الخمسة الكبرى للشخصية، الكفاءة الذاتية، السعادة، تحليل المسار .

\title{
Causal Relationship Modeling of the Big-Five Factors, Self-Efficacy, and Happiness of Jordan University of Science and Technology Students
}

\author{
Khaldoun Al-Dababi* \\ Rabe'a Al- Dababi \\ Imam Abdulrahman Bin Faisal \\ University, Saudi Arabia
Jordan University of Science \& Technology, Jordan \\ Abdulsalam abdelrahman \\ UNRWA, Jordan
}

\begin{abstract}
The purpose of this study was to unveil the causal relationship of the big-five factors, self-efficacy and happiness for JUST students. Based on scientific foundations, it constructed a proposed causal relationship model using path analysis for interpreting happiness. To achieve this goal, the Big Five Factors by John, Donahue \& Kentle, (1991), the General Self-Efficacy Scale of Schwarzer \& Jerusalem, (1995), and Oxford Happiness Inventory were employed. The sample consisted of 377 students chosen on availability grounds. The results showed no statistically significant differences between the proposed and the optimal causal relationship models due to high matches on AGFI=0.942; NFI=0.986; RMSEA=0.069; GFI=0.994; IFI=0.991; TLI=0.933; and CFI $=0.990$. Thus, the model construes the relationships proposed and represents the optimal causal relationship model for the variables of the study.
\end{abstract}

Keywords: The big-five-factors; self-efficacy; happiness; path analysis.

*aa_salamhani@yahoo.com 


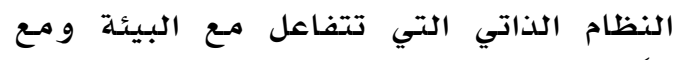
الأيات التحفيزية الأخرى (Haackett, 1987)،

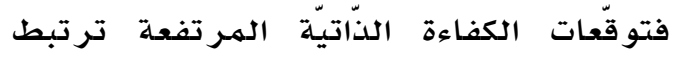

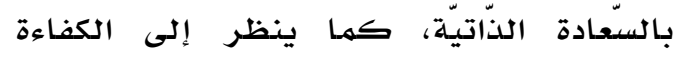

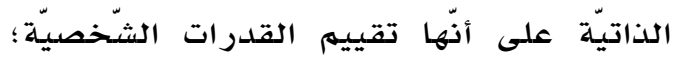

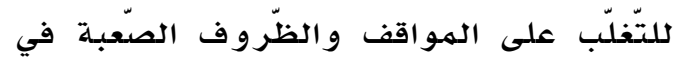

Karademas, Kafetsios \& ) المستقبل

.(Sideridis, 2007

Happiness السعادة

معظم الدراسات النفسية في ميدان الانفعالات توجه اهتمامها نحو الاضطرابات النفسية

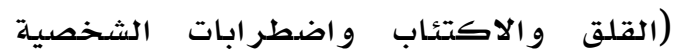

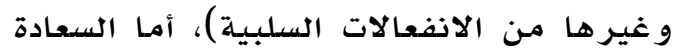
بما تتضهمنه من الهشاعر و الخبر ات الإيجابية

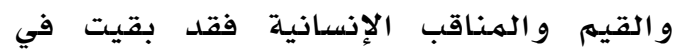

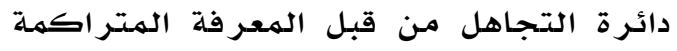
في ميدان علم النفس لعقود مـن الزمن، أما في الوقت الحالي فقد شهدت دراسـة السعادة

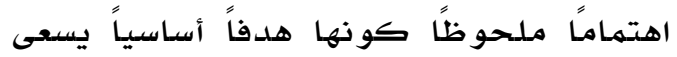

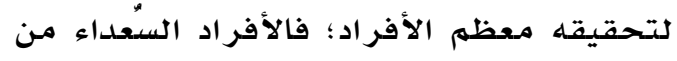

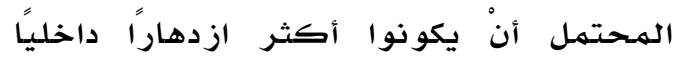

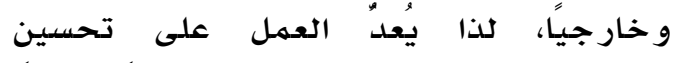

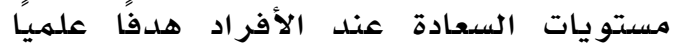

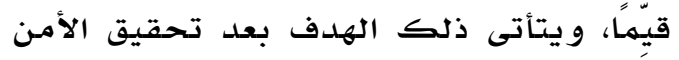

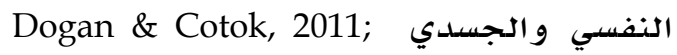
.(Khan, 2009) Nistor, 2011

ويعتبر مصطلح السعادة من المصطلحات

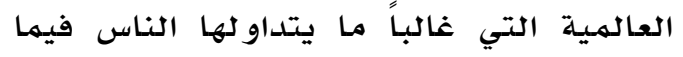

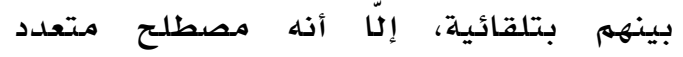

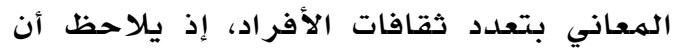

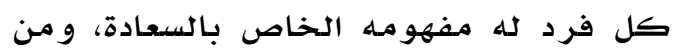
هنا أجمـع العلماء على وضع معايير تتضمن

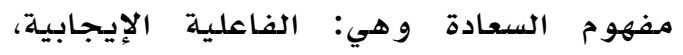

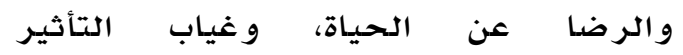

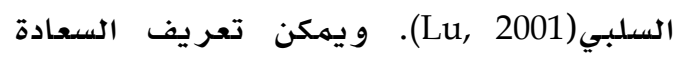

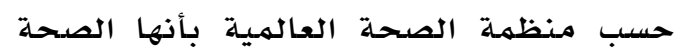
و تعني حالة من الكمال الجسدي والعقلي

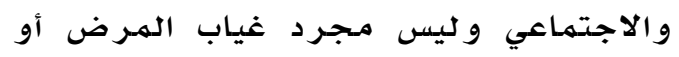

غدت السعادة واحدة من الهفاهيم الأكثر أهمية في مـجال علهم النفس الإيجابي، لها لها من اثر في تحقيق التوافق الذاتي وإيجاد

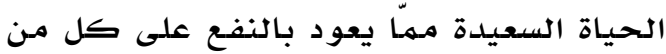

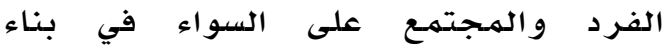

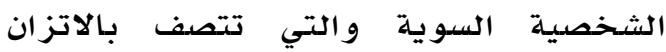

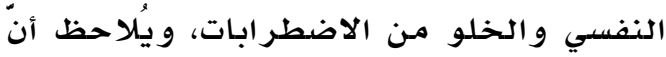

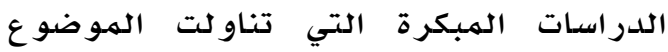

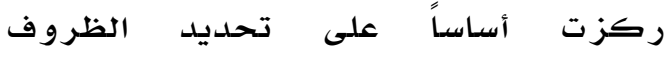
الخارجية التي تؤدي إلى السعادة، وتبيّن في

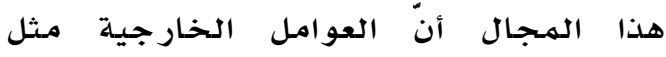

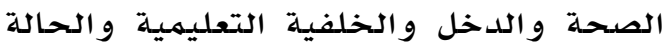
الزواجية لا تمثل سوى إسهام بسيط من تباين درجات السعادة وومن هنا بدأ تحول

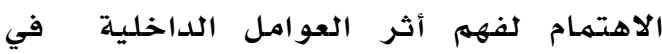

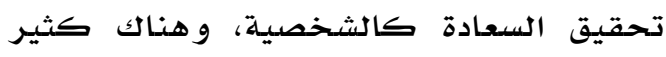

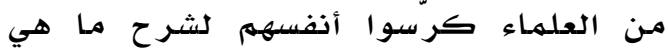
السعادة في منجال علهم النفس الإيجابي

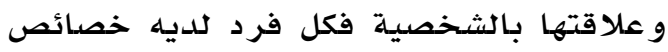
شخصية التي تفرده وتؤثر على كيفية استجابتهم لبيئته.

و تؤثر السمات الشخصية الإيجابية والسلبيـة

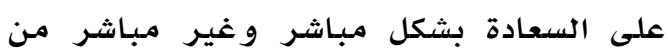

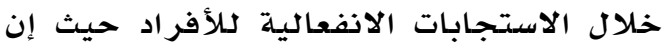

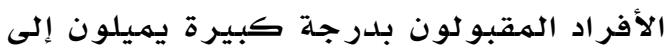
تجربة مستويات عالية من الإيجابية و لديهم ردود فعل عاطفية أقوى لكلأحداث الإيجابية

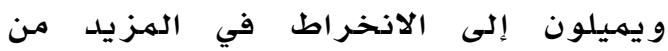
السلوكات الاجتماعية التعاون

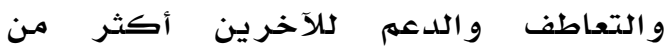
نظرائهم العصابيون الذين تكون تجربتهم أكثر سلباً وخصوصاً في ردود فعل الثديد الثيدة لكلأحداث السلبية (Graziano \& Tobin, 2009). فالشخصية بناء داخلي له تأثير كبير على الإنى

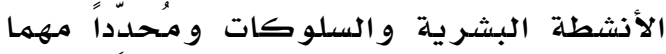
للأفكار كما تعتبر الكفاءة الذاتية من أهم مصادر تكيف الشخصية، حيث أنها ليست سمة سلبية أو مـميزة و لكنها جانب ديناميكي من من 
و تتأثر السعادة بهمجهوعة مـن العوامل أهمهها:

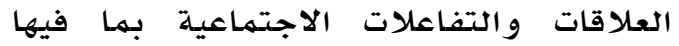

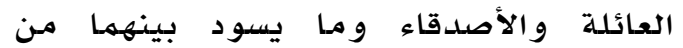

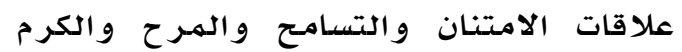

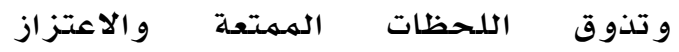

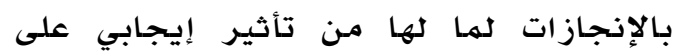

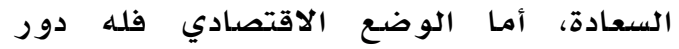
أسساسي؛ إذ يعتقد كثير من الأفر اد أنّ الثروة الثادئ

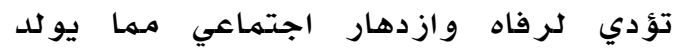

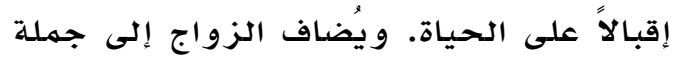

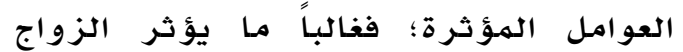
إيجابيًا في تحقيق السعادة بين الأفراد، أما فئ

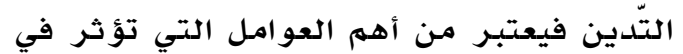

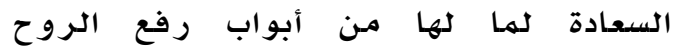

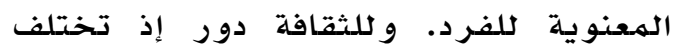

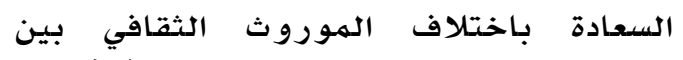
الهجتهعات، أما نهط الشخصية يعد من فئ

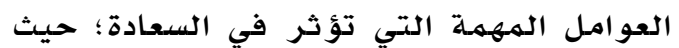
إن الشخصية الانبساطية تمتاز بسعادة بشكل أكبر من الشخصية الانطوائية ) Diener \&

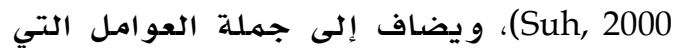
يمكن أن يكون لها دور في سعادة الأفراد:

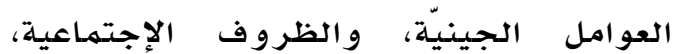

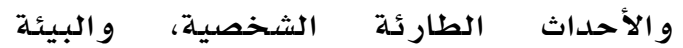

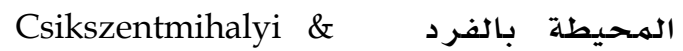

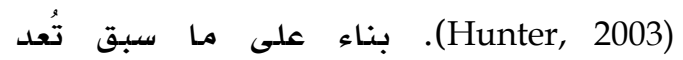
السّعادة حالة و ليس سمة أي أنها تتغير تبعًا

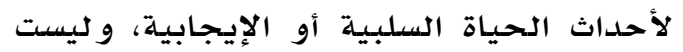

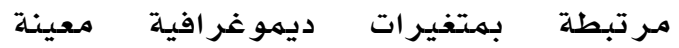
كالعمر أو الجنس أو الذكاء ( Langevin, كريطهان

\section{Self Efficacy الكفاءة الذاتية}

تعد اعتقادات الأفراد حول قدر اتهم مكوناً

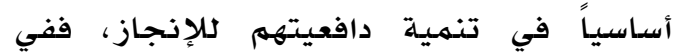

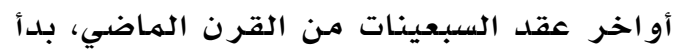

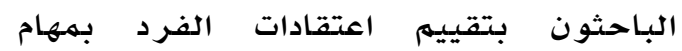

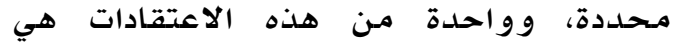
الكفاءة النذاتية، حيث قدّم بـاندور ا (Bandura) عام laVV نظريته المعرفية الاجتمـاعية وفيها

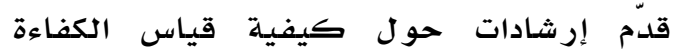

الوهن (World Health Organization, 1997).

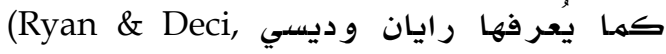

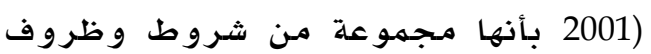
من تجارب وخبرات التكامل. أما سليـجمان (Seligman, 2004) أو شعور يتضمن الرضا، والحب، والمنفعة،

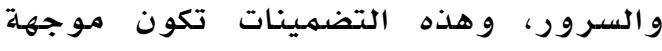

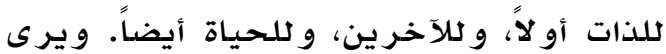
باربر (Barber, 2010) السعادة على وانى أنها حالة الشخص العاملة من الإيجابية والتفاؤل

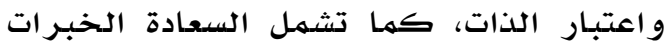
المتكررة من الانفعالات الإيجابية.

إن السعادة لها مكونين الأول السعادة الذاتية أو اللدة Subjective Well-) (SBW) Hedonic Being)، و الذي يركز الأه على السعادة و الهشاعر

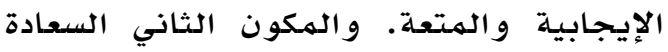
Psychological ) (PBW) Eudemonic النفسية ونية الايجية ) (Well Being الإنسـان لقدراته و تحقيق الغرض مـن الحياة،

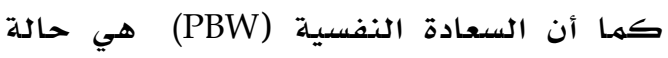

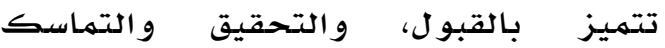

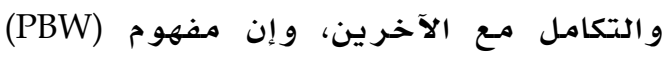
يختلف عن (SWB) بأن الأو لى لها ستة ستة أبعاد (الاستقلال و النمو الشخصي و وتقبل الذات و الحياة الهادفة والاتقان والارتباط الإيجابي) وهذه الأبعاد الستة مـرتبطة إيجابياً بالصحة الصة العقلية و الجسدية والتي ليس من الضروري

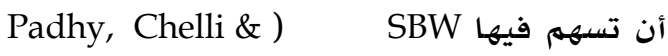
(Padiri, 2015

ويرى ريتشارد (Richard, 2005) أنّ هناك

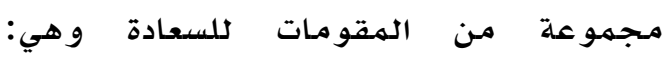
الاستقرار: وتعني التمسك بأحكام السعادة عندما تتحقق، والتحديد: ووهي قدرة الأفراد على تحديد الحياة الفضلى، والتأكيد على الوقت: وتعني تقييهم للحياة، لذا يمكن الحكمم

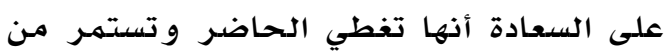
الماضي و وتتوقع المستقبل، و الوعي: وهو ودو إدراك الفرد للسعادة في المواقف المـختلفة. 


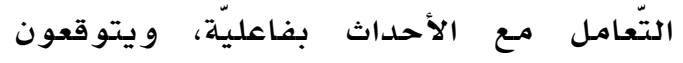
النجاح في التغلب على العقبات، و أنّ الهثابرة

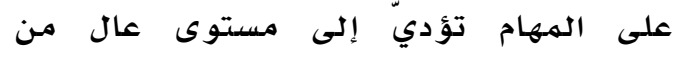

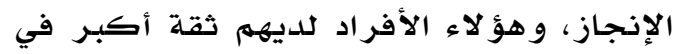

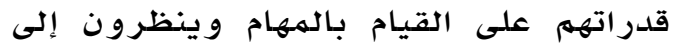

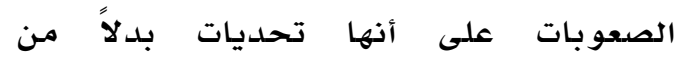

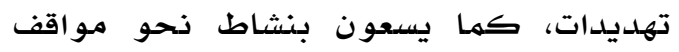

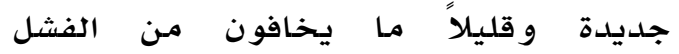

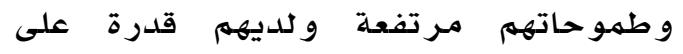
Schultz \& ) التفكير التحليلي وحل المشكلات

.(Schultz, 2009

و تتطور معتقدات الكفاءة الذاتية اعتمـاداً على رلى

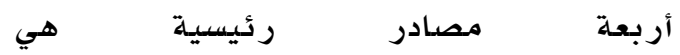
Maddux, Jones, 2011; Seifert \& Sutton, 2009) :(Schunk \& Mullen, 2012 ; 1995 ;

خبر ات الإتقان (Mastery Experiences) توفر

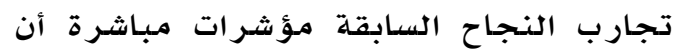

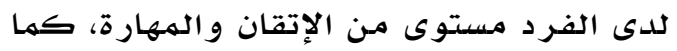

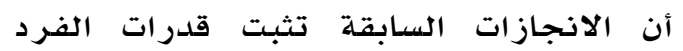

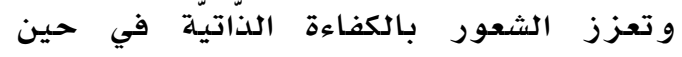

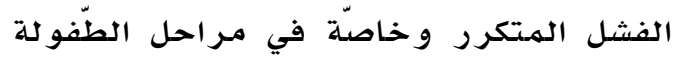

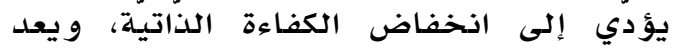

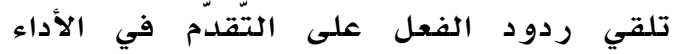

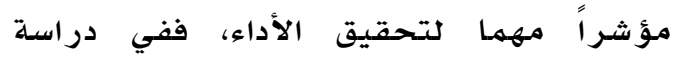
أجر اها لي ماكألوي ووهامر دنكان تشاميتون (Li, McAuley, Harmer, Duncan \& لقياس أهمية ردود Chaumeton, 2001) الفعل والتّقدّم لتحقيق الأداء فقد وجداء التدا أندان الذّين تلقّوا ردود فعل إيجابية على الفيق أدائهم كانت الكفاءة الذاتية عالية في مقابل الذين تلقوا ردود فعل سلبية كانت كفاءتهم الذاتية منخفضة. الخبرات و والتجارب غير فير المباشرة (الابدالية) (Vicarious Experience)

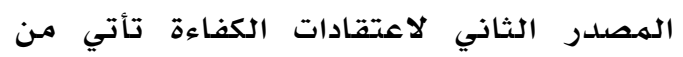

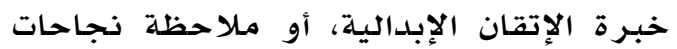

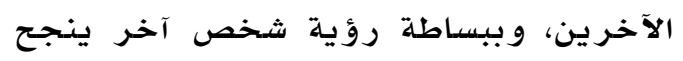

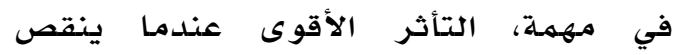

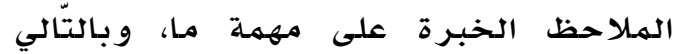

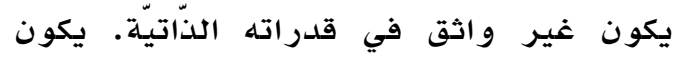
التأثير أقوى عندما يكون النّموذذج هو شخص

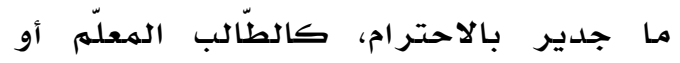

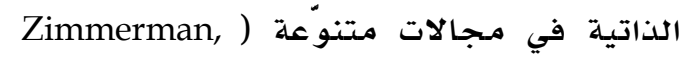

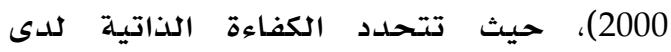
الأفراد بمدى قدرتهم على تلبيية المعايير

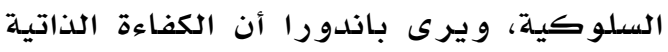
هي الإحساس أو الشعور بالكفاءة في التأقلم

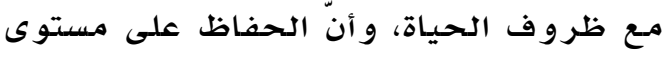

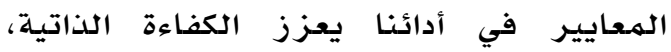

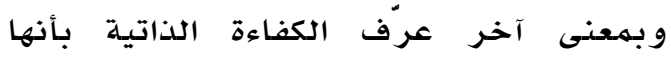

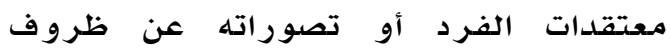

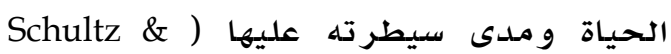
.(Schultz, 2009

إذ يسعى الأفر اد إلى السيّيطرة على الأحداث

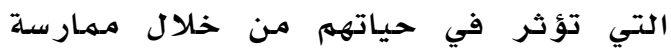

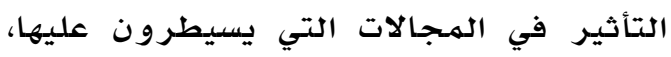

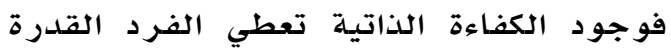

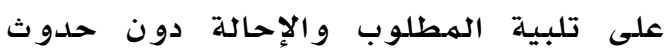
غير المرغوب فيه (Bandura, 1995). و لتحقيق السّيطرة على ظروف الحياة فوائد

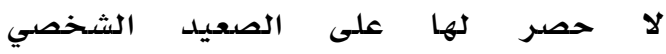

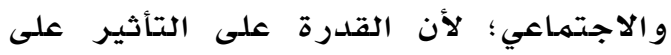
النتائج تجعل الفرد أكثر قدرة على الاعئ التتبؤ،

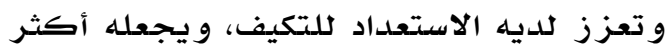

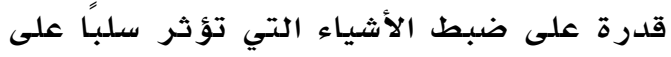
حياته كالخوف و اليأس و الدلامبالاة ( Schultz (\& Schultz, 2009 أمّا الأفراد الذين يمتازون بالكفاءة الذّاتية

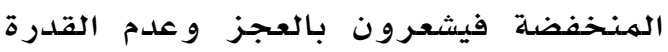
على السيطرة على أحداث الحياة، و يعتقدون

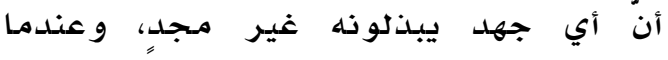

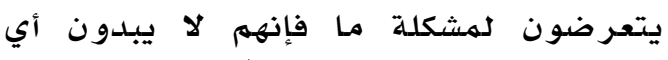

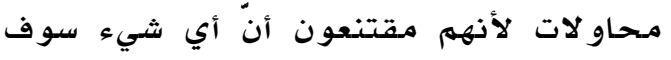

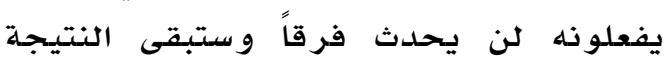

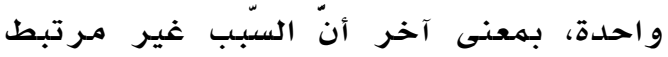
بالنتيجة (Bandura, 1995) كما أن؛ انخفاض الكفاءة الذاتية ليُدمر

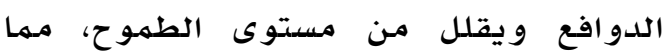

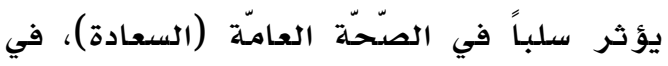

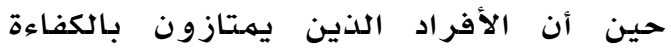

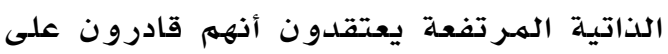


نظرية الكفاءة الذّاتية تقدّم إطار عمل لفهم

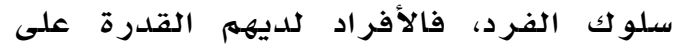
التّحكم الهادف في سلوفهم و وعلى بيئاتهم؛

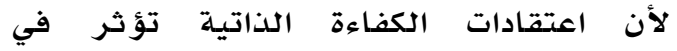

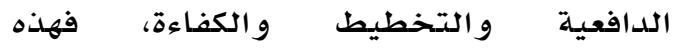

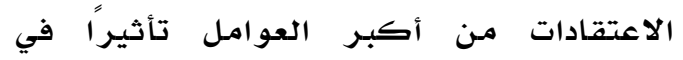
السلوك، وون أجل الحصول على فهم أوضـح

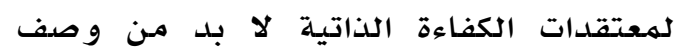

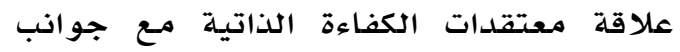

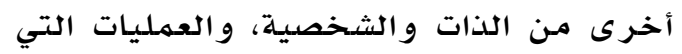
يتتم من خلالها تشكيل معتقدات الكفاءة الذاتية (Jones, 2011).

Big Five العوامل الخمسة الكبرى الشخصية Factors

لقد حظي موضوع الشخصية في مجال علم النفس اهتمام كثير من العلماء و الباحثين

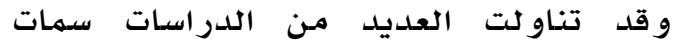

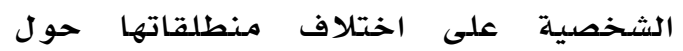

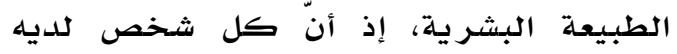

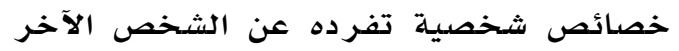
وأن هذه الخصدائص يمكن أن توصف بأنها تؤثر على كيفية الاستجابة للبيئة. وتتميز الشخصية عن غيرها من موضوعات

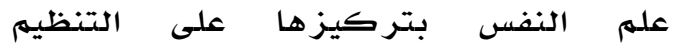
الديناميكي المعقد داخل الفرد و وارتبـاطها بالفروق الفردية في الوظائف النفسية،

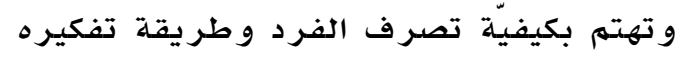

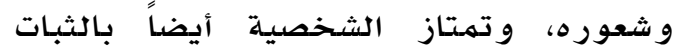
و الاستقر ار النسبي، و أن الشخصية هي العامل

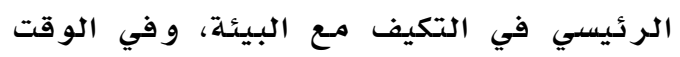
نفسله يسعى علماء نفس الشخصية للتوصل

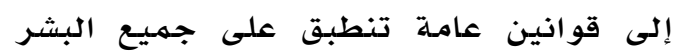

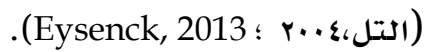

و يختلف تعريف الشخصية باختلاف المنحى

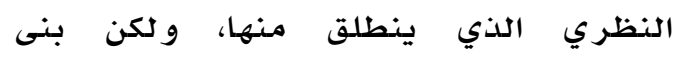

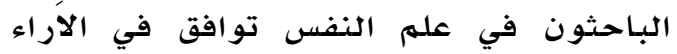

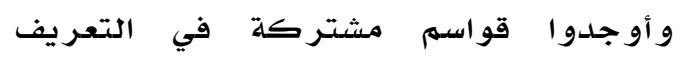
مفهوم الشخصية إذ يعر فها ماكري وجون وجون بأنها "نموذج (John \& Mccrae,1992, p176)
الزّميل ذوي القدرة. حتى في مثل هذه الظروف فإنّ الخبرة الإبدالية ليست في مثل فيل تأثير الخبرة المبـاشرة، وهذا أمر ليس صعبًا تصور ه.

ويُعد الإقناع اللفظي (Verbal Persuasion)

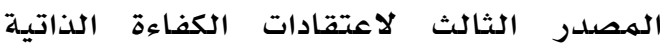
و الذي هو التشجيع، من خلال إقناع شخص

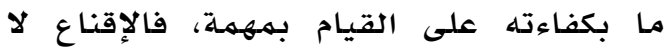
يكون كفاءة ذاتيلة مرتفعة في حد ذاته، لكنهـ

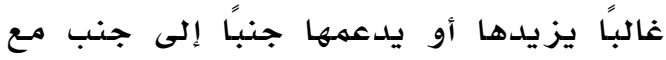

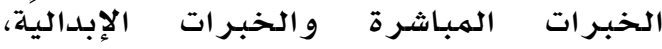
وخصوصسا عندما يأتي الإقناع من أكثر من

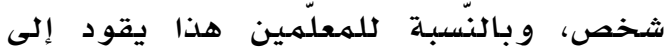

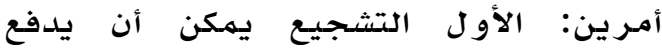

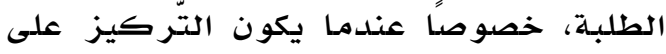
مهمات مححددة قابلة للتحقيق، فهو يمكن أن أن يدفع الطلبة بقول أشياء من قبيل مهندة "أعتقد

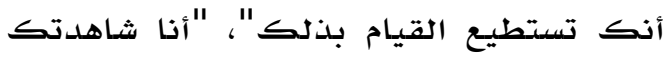
تقوم بهذا الأمـر من قبل، لذا أعرف أنكام بلك تستطيع القيام بذلك مـجددا". فأما التّطبيق الثاني للمعلمين فهو دعم التشجيع بإعادة ترتيب المهمات المقدمة للطالب بحيث تكون قابلة للتحقيق، وضهمن قدرات الطالب.

مستوى الإثارة الفسيو لوجية و العاطفية (Physiological And Affective States) المصادر الثلاثة السابقة لاعتقادات الكفاءة

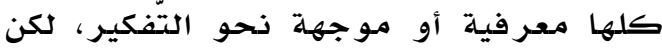

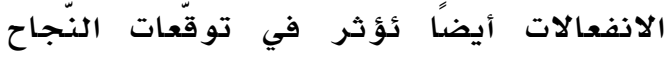

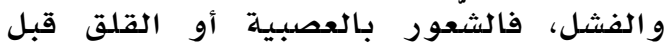

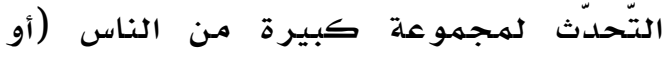

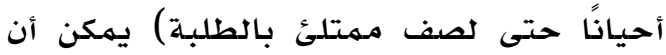

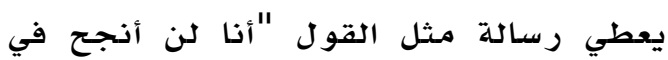
القيام بذلك" حتى لو كان ثمـة سبب وجيه لتوقع النجاح، لكن المشاعر الإيجابية يمكن

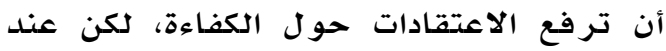

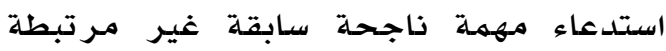

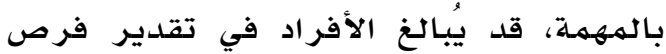

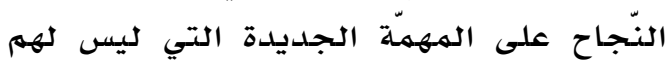
فيها خبرة سابقة، وبالتالي فهي ليست في وضع يسمـح لهم للتنبؤ بكفاءتها. 
استخدامها لفهم أنفسهم و فهم الآخرين، و تعود أصول العوامل الكبرى للشخصية إلى الورقة التي قدمها العالم فر انسيس جالتون

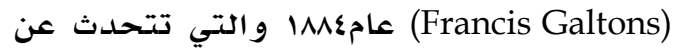
قياس الشخصية، والتي اقترحت أن الفروق

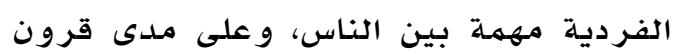

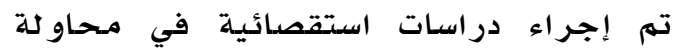
لتصنيف الآلاف من الصفات الشخصية وراء وفي لمات عام .197 و مـع ظهور التقنيات الإحصائية

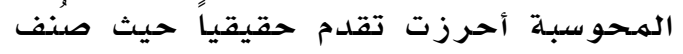

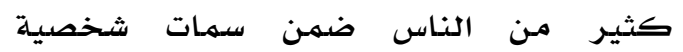
محددة و أدت هذه التحليلات إلى شبه إجماع

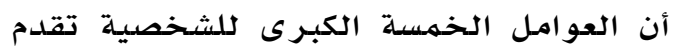
تفسيرًا عالميًا للفروق الفر الفرية في الشخصية

.(Dale \& Harrison, 2017)

و تتألف الشخصية وفقاً لنـموذج العوامل

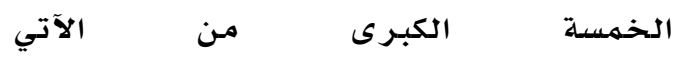
McCrae, \& Costa, 1997; John \& ) (John \& McCrae, 1992 ; Srivastava, 1999

- الانبساط (Extraversion): ويهتاز هؤلاء الأفر اد بالمشاعر الإيجابية و العواطف و الميل وليل

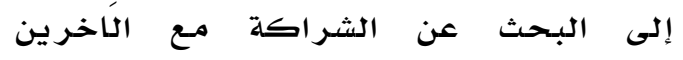

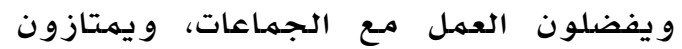

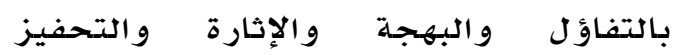

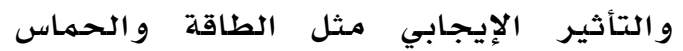
و الدافعيـة.

- المقبو لية (Agreableness): و هي الهيل إلى الثقة و المسايرة و الرعاية وير وير اعي مشاعر

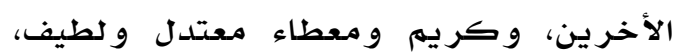

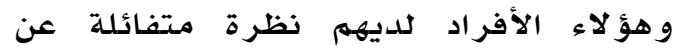

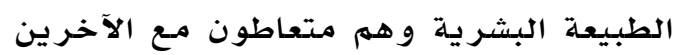

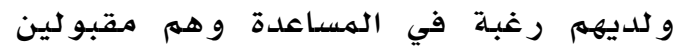

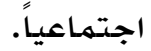

- يقظة الضمير (Conscientiousness): يمتاز

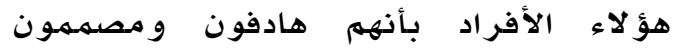

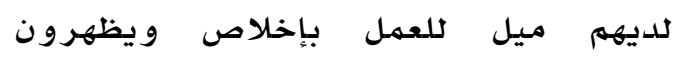
انضباط ذاتي ويقومون بالعمل دون التطلع

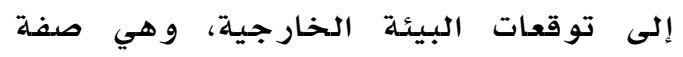

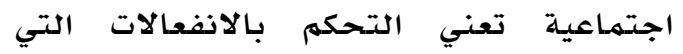
تسيطر وتيسر السلوك الموجه الهـ نحو الهدف
يقوم على تصور مؤداه أنه يمكن وصف اقدئ

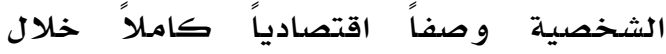
خمسـة عوامل أساسية هي : العصابية،

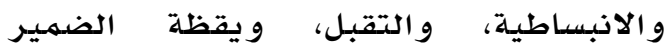

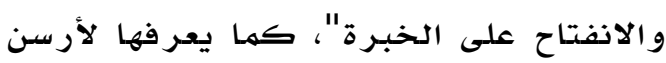
وبوس (Larsen \& Buss, 2005, p4): بأنها "مـجمو عة من السمات و الأَيات النفسية داخل

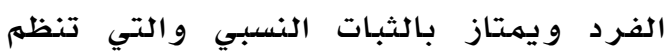

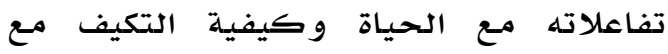

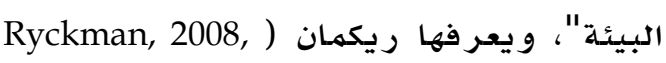

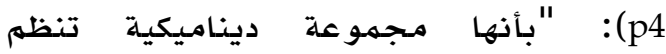
الخصائص التي يمتلكها الشخص و إدركاته

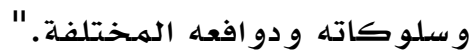

و في غضون العقدين الماضيين كان هناك تبايناً في وجهات نظر العلماء تبعاً إلى الأطر الهر النظرية التي ينتمون إليها، ومن هذه الأطر منحى السهات الذي ينظر إلى الشخصية أنها

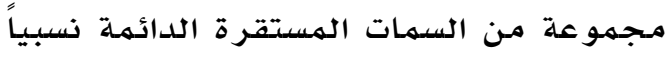

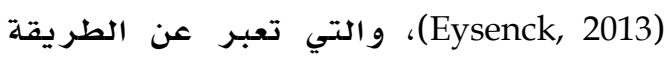
التي يشعر بها الفرد وطريقة تفكيره، وأن

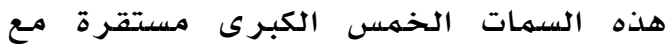

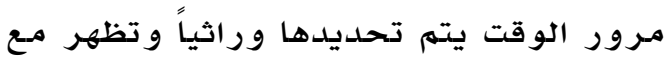
الولادة مـع أن البيئة تلعب دوراً أيضاً بها بها (Gosling, Rentfrow \& Jr, 2003; McCrae \& و يعد نهوذج العوامل الخمسسة الكبرى من أبرز النهماذج قبولاً و والأكثر الهول شيوعاً في نظرية السمات وفي علم النفر النفس النس

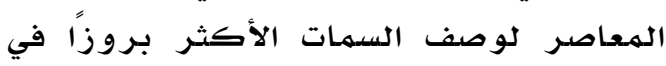
الشخصية وسميتِت بالخمسة الكبرى لانعكاس عظمتها الكامنـة حيث يعكس كل عامل عدد كبير من العوامل التي تمثل الشخصيـة على

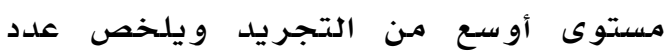
كبير من خصائص الشخصية الهميزة والأكثر تحديداً John \& Srivastava, 1999,

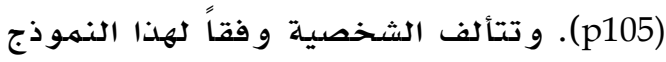
من خمسة سمات يقظة الضمير والعصدابية

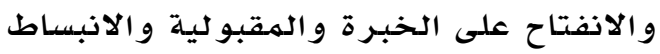
(McCrae \& John, 1992)

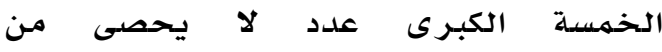
السلو كات وتقدم لغة مشتر كة تُمكّن الأفر اد لخدي 
تناول الكفاءة الذاتية كمتغير وسيط، تكونت

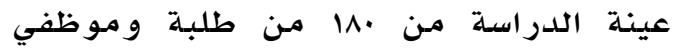

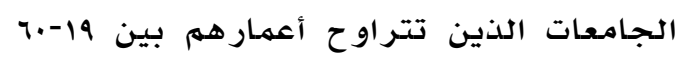

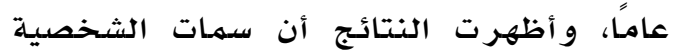

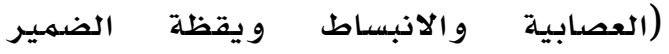
والانفتاح على الخبرة) تؤثر على الرضا عن والى

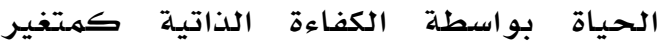
وسيط، كها بيّنت النتائج أن الكفاءة الذاتية الذية النية النية

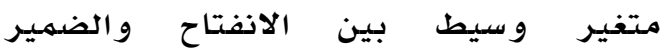

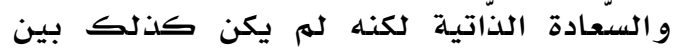

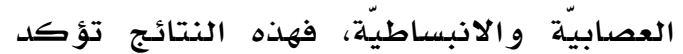

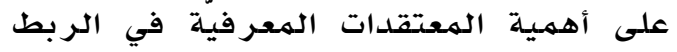

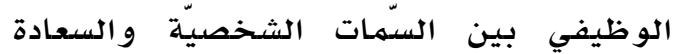
الذاتيّة.

و في دراسة أجر اها ديبا و هوناغوند وهانفال (Deepa, Hunagund \& Hangal, 2014) للكشف عن العلاقة بين الكفاءة الذاتية و السعادة لدى الشبـاب الخريجين تكونت عينـة

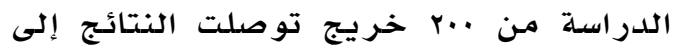
أن هناك علاقة إيجابية بين الكفاءة الذاتية

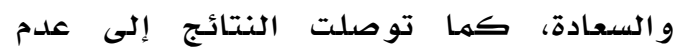

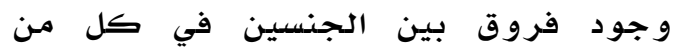
الكفاءة الذاتية و السعادة.

كما قامت تيف (عابr) بلدراسة هدفت إلى الكشف عن العحلاقة بين العوامل الخمسلة الكبرى للشخصية و الرضا عن الحياة للدى عينة من طلاب الجامعة الأردنية تكونت عينة الدراسـة من عَس من طلبـة الجامعة الأردنية.

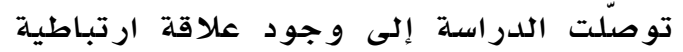
عكسية بين العصابية و والرضا عن الحياة

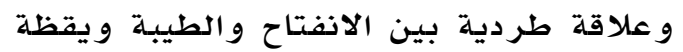

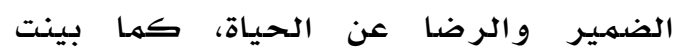
النتائج ارتفاع مستوى العصابية و ويقظة الضمير عند الذكور مقارنة بالإناث، وأن مستوى هذين العاملين كانت أعلى لدى لدى لدئ طلبة الكليات العلمية مقارنة بالإنسانية ولم الم تظهر فروق على متغير السنة الدراسية

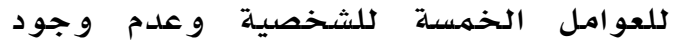

والتفكير قبل القيام بالتصرفات و وتأخير الإثباع ويعملون وفق معايير وضدوابط و تخطيط و تنظيم و تحديد أو لويات المهام. - العصابية (Neuroticism): يمتاز هنا الأفر اد بالانفعالات السلبية والتي هي عكس الصسلابة

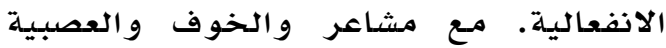
و الحزن و التوتر و الغضب و الشعور بالذنب.

(Openness to الانفتــاح علـى الخبــرة Experience)

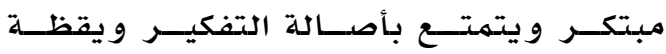

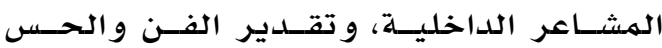
الهـر هــف للجهمــال و هــؤ لاء الأفـــر اد لــديهم استعداد لإبداء أفكار جديدة غير تقليدية. تستحوذ دراسـة السعادة على اهتمـام بـالغ مسن قبل الباحثين في مختلف المجالات النفسـيـية نظراً لارتباط هذه الحياحئ في مخلة بالصسحة النفسـية الهـالات النفية

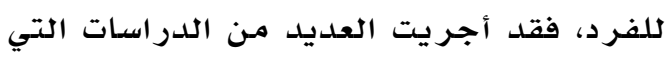

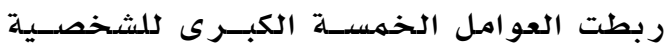

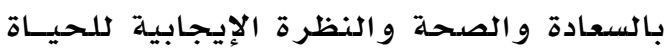
و الكفاءة الذاتية، وومن هذه الدر اسـات: بـاية قام أبو هاثــم (·r.r) بلدراســة هـدفت

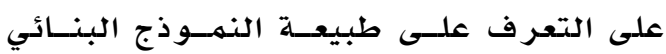
للعلاقــات بــين الســعادة النفسـيـة و العوامـل الخمسسة الكبــرى للشخصـيـة وتقـــير الــذات

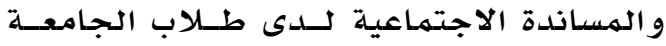

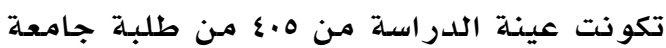

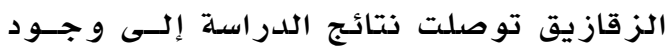

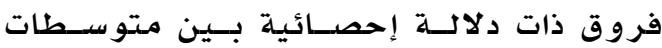

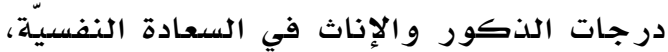

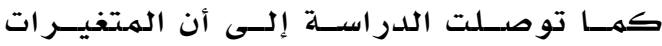

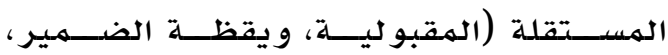

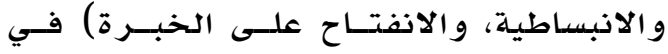

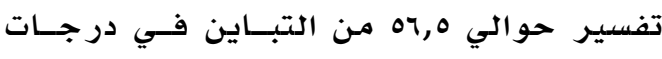
المتغير التابع (السعادة النفسية).

كما قام كل من ستروبل و تماسـان وسبور لي ( Strobel, Tumasjan \& Sporrle,

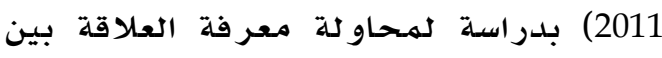

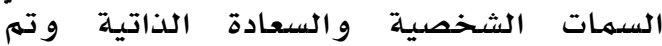


الذاتية و واحترام الذات و والسعادة الذاتية تكونت عينة الدراسة من 007 من طلبـة الذين

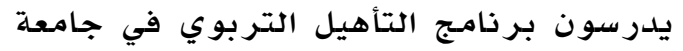

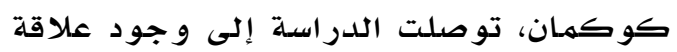
بين الكفاءة الذاتية و السعادة.

و في السياق نفسه أجرى زهانج ( 2016) دراسـة للكشف عن العلاقة بين افئ السمات الشخصية والكفاءة الذاتية وبين الرضا عن الرنا

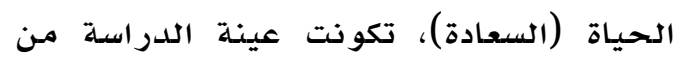

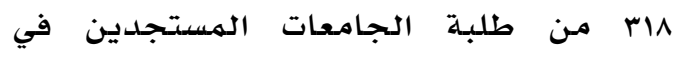
الصين، أظهرت النتائج أن الكفاءة الذاتية ذات قيمة محدوودة في التنبؤ بالسعادة الذاتية.

وبعد استعراض نتائج الدراسـات السابقة لوحظ أن نتائج الدراسات السابقة له تقطع

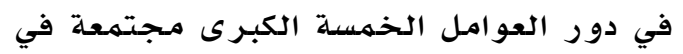
تحقيق السعادة كما يظهر في دراسـة أبو البو

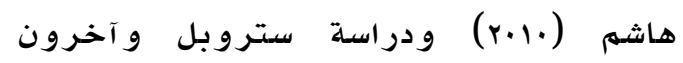
(Strobel et al., 2011) وساتيسي (Emine \& Satici, 2015) و ودراسة إسة Chavan \& Badgujar, تشافان و بادجوجار (2016)، أما فيما يخص علاقة الكفاءة الذاتية مـع السعادة فلهم تقطع ايضاً الدراسـات السابقة في طبيعة هذه العلاقة ففي دراسلة صديقي و ودراسـة إروزكان و آخرون (Siddiqui, 2015) بينت أن ثمهة علاقة (Erozkan et al., 2016) بين الكفاءة الذاتية و السعادة في حين أظهرت

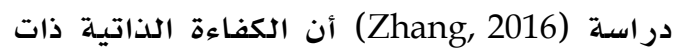
قيمة محلدودة في التتبؤ بالسعادة الذاتية. كما يـلاحظ من خلال الدرّاسـات السـابقة عدم تطرق الباحثين لدراسة الثلاث متغيرات مجتمعهةً، أما على الصعيد العربيد بي فلا توجد

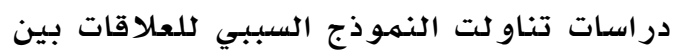
العوامل الخمسة الكبرى للشخصية و الكفاءة

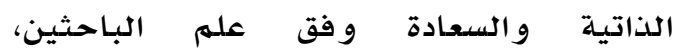

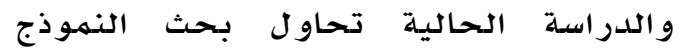
السببي للعحلاقات بين للشخصية و الكفاءة

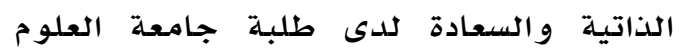
و التكنو لوجيا الأردنية، و ومن أجل توضيح

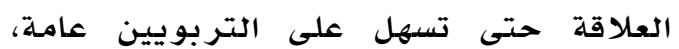

فروق لمستوى الرضا عن الحياة تعزى للمتغير ات الجنس والكلية و السنة الدر اسية.

كما قام إيمين و ساتيسي ( Emine \& Satici, 2015) بدراسـة هدفت للكشف عن العلاقة بين السمـات الخمسة الكبرى للشخصية والسعادة الذاتية تكونت عينة الدراسـة من وجس مهمن يتراوح أعمارهم بين 11-بـ توصلت عينة

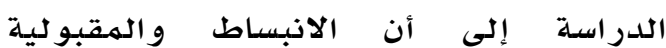
والانفتاح ويقظة الضمير كانت مؤشرات

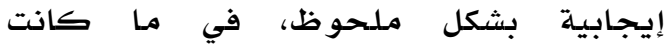

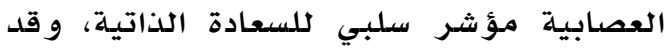

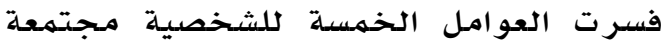
ما نسبته بr\% من التباين في السّعادة . و في دراسـة أجر اها صديقي (Siddiqui, 2015)

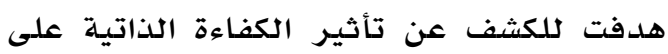
الرفاه النفسي للىى طلبـة المـرحلة الجامعية

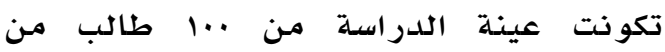

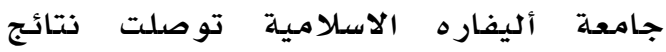
الدراسلة لوجود علاقة ارتباطية بين الكفاءة الذاتية و الر فاه النفسي، وكما ولودا أن الإسدهام

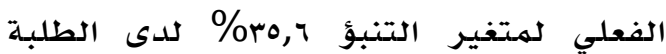
الذكور في حين كان الإسهام للدى الإناث .\%r., \&

و في السياق نفسه أجرى كل من تشافان وبادجوجار (Chavan \& Badgujar, 2016)

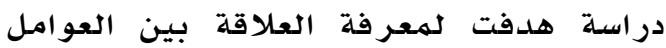

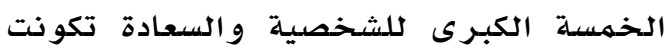
عينة الدراسلة الدراسلة من اسبر طالب مهن

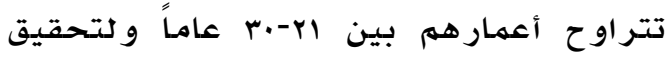

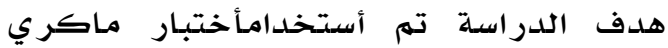
وكوستا (NEO-FFI) لقياس العوامل الكبرى للشخصية و قائممة أكسفورد لقياس السعادة توصلت الدراسـة إلى أن عوامل الشخصية

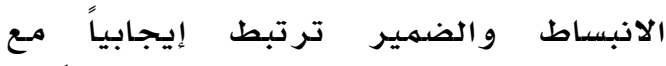
السعادة في حين أن العصدابية ترتبط سلبـا مـع السعادة و الانفتاح لا يرتبط مـع السعادة.

و في دراسة أجراها إروزكان دوغان Erozkan, Dogan \& Adiguzel, ) أديفوزل 2016) هدفت للكشف عن العلاقة بين الكفاءة 
الذاتية بالسعادة، وذلك من خلال الإجابة عن

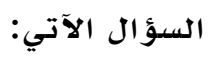

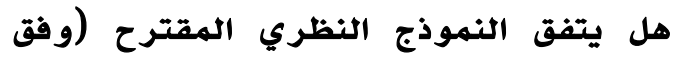
الأسس النظرية والمنطقية ونتائج الدراسات

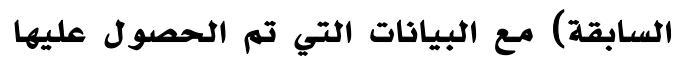

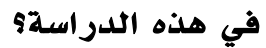

أهمية الدراسة

أهمية نظرية: تنبع أهمية الدراسلة الحالية كونها تحاول البحث في العلاقات السببية

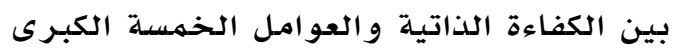
للشخصية في تحقيق السعادة الأمر الذي يعد

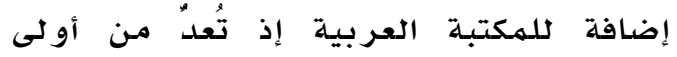

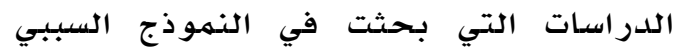

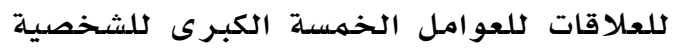
و الكفاءة الذاتية و السعادة مـجتمعةً. أهمية تطبيقية: تتمثل في الإفادة من نتائج

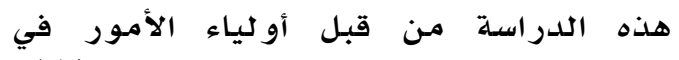

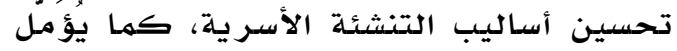

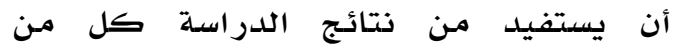

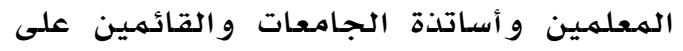

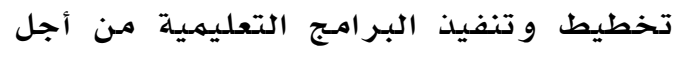
تطوير أساليب ووسيائل تعليمية و وتطوير المناهج بشكل يعمل على رفع معتقدات الفرد

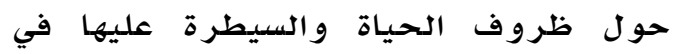
سبيل تحقيق الكفاءة الذاتية والسعادة.

محددات الدراسة وحدودها

يتحدد تعميم نتائج هذه الدراسـة بعينة

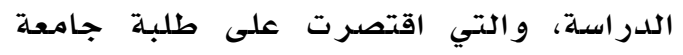

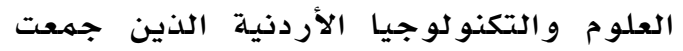

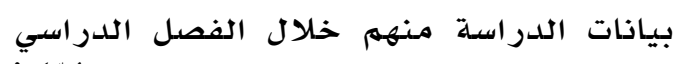

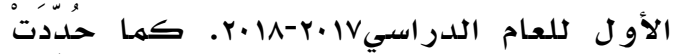

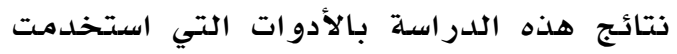

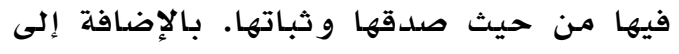
المنهج الذي استخدمـه الباحثين وهو المنهـج الوصفي التحليلي. أما حدود هذه الدراسلة فهي الحسدود البشرية، إذ اقتصرت الدراسـة على طلبـة جامعة العلوم

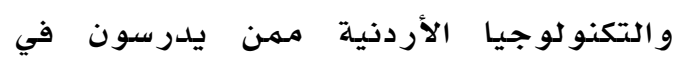

و العاملين على التعلهم الجامعي خاصدة وضع البرامج و التركيز على علم النفس الإيجابي بأفضل شكل مـمكن.

مشكلة الدر اسة و أسئلتها يعاني طلبة الجامعات من مشكلات عديدة نتيجة انخفاض مستتوى السعادة، والتي من من من مان مظاهر ها العبوس الدائم، والاستجابات

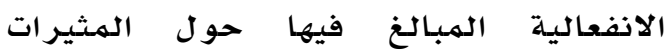
الهحيطة، وانتشار ظاهرة العنف بينهم، بالإضافة إلى العزوف عن المشاركة في الأنثطة الجامعية، وغير ذلك الكير من الأنماط السلوكية السلبية التي لها آثار غير مر غوبة التها

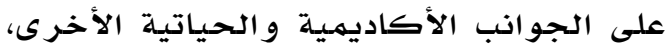
وقد لوحظ أن لأنماط الشخصية التي يتمتع

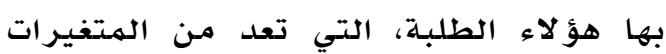
المحددة للفكر و السلوك واءكو الانفعال، تأثير على الحالة الإنفعالية التي يشعرون بها، وومن ذلك حالة السعادة، والشعور بالكفاءة الذاتية؛ فربها تؤدي عوامل الشخصيلة الكبرى إلى رفع مستوى الكفاءة الذاتية حيال الههمات أو إلى الشعور بـانخفاض الكفاءة

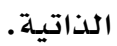

أما السعادة فهي ظاهرة معقدة تتداخل فيها

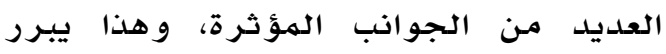

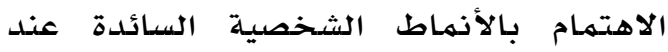

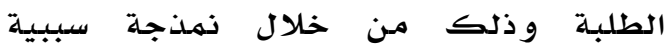
للعلاقات بين العوامل الخمس الكبرى فئ في الشخصية و الكفاءة الذاتية و علاقتها بالسعادة،

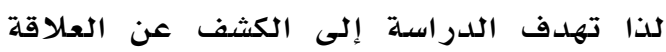
بين المتغيرات ووضع نموذج سببي يوضح

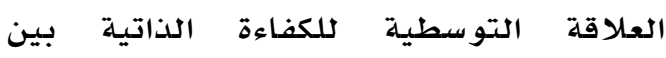
العوامل الخمسـة الكبرى للشخصية و السعادة. كما تبرز المشكلة أيضاً عند الانتقال من مرحلة تعليمية إلى أخرى؛ إذ تتغير معتقدات الفرد حول ظروف الحياة وقدرتهم على إلى السيطرة عليها مها يؤدي إلى ظهور تهديد

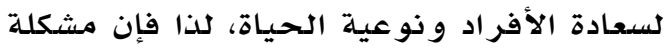
الدراسة الحالية تتناول تحديد العلاقة بين

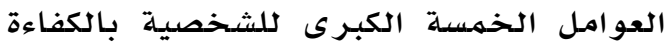




\section{الطريقة و الإجر اءات}

مجتمع الدراسة

تكون مـتمهـع الدراسة من جميع طلبـة جامعة

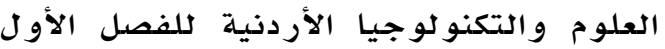

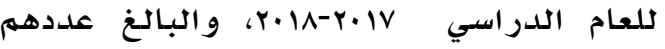
حسب إحصدئيات عمادة القبول والتسبريل • . .

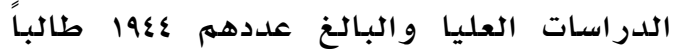

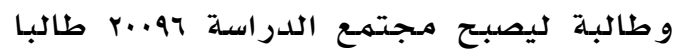

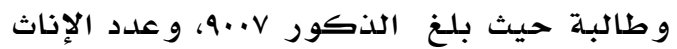

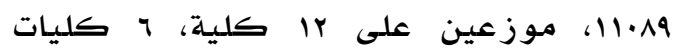
طبية وr كليات هندسية وr كليات العلمية.

عينة الدراسة

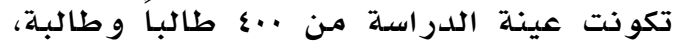
تم استبعاد استجابة r r طالبا وطالبة لعدم الجدية في الاستجابة أو وجود نقص في

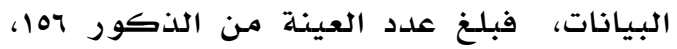
و عدد الإناث الY آم، موزعين على التخصصات الطبية بواقع عالr طالبا وطالبة والتخصصات

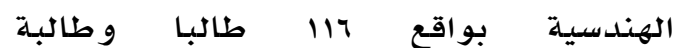

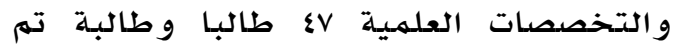
اختيارها بالطريقة المتيسرة و كانت وحلدة الاختيار هي الشعبة.

\section{منهجية الدراسة}

استخدم في هذه الدراسلة المنهج الوصفي

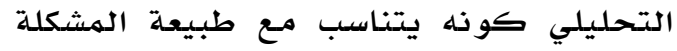

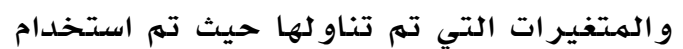
النهوذج السببي، ويتهثل الهـدف من النهموذج

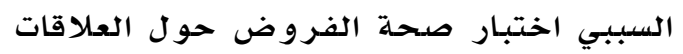

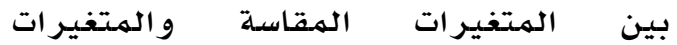
الملاحظة.

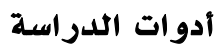
لتحقيق أهداف الدراسـة تم استخدام ثلاث

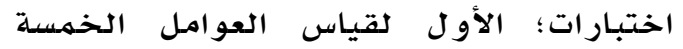
الكبرى للشخصية واختبار الكفاءة الذاتية

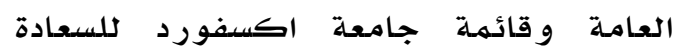
للكشف عن مستوى السعادة لدى أفراد عينة

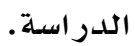

مرحلة الشهادة الجامعيلة الأولى، والحلدود الزمانية إذ أجريت الدرراسلة في الفصل الفهل

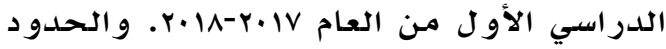

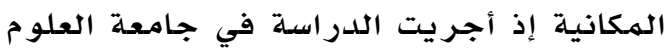
و التكنو لوجيا الأردنية التي تقع ضهمن مدينة

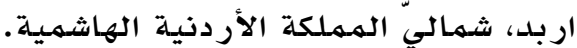

التعريفات الاصطلاحية والإجرائية

Big Five العوامل الخمسة الكبرى للشخصية (Factors)

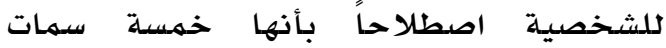

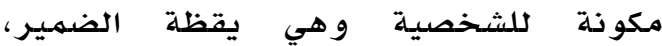

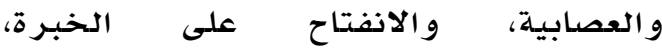

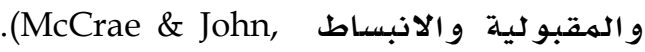

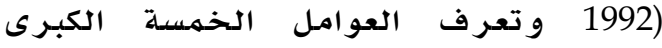

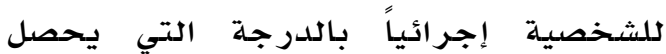

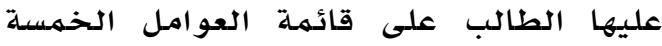

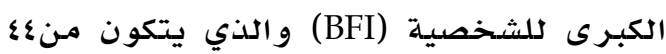
فقرة موزعة على خهسـة أبعاد. الكفاءة الذاتية (Self Efficacy): تعرف الكفاءة

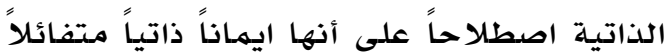
باعتقاد الفرد بأنه يستطيع أداء مهام جديدة

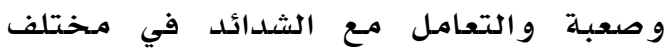
مجالات العممل البشري بحيث تسهل تحديد الأهداف واستتثمار الجهد و الثبات في مواجهة الحواجز و التعافي من النكسـات بحيث يمكن

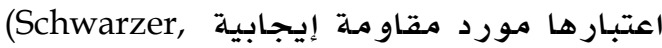

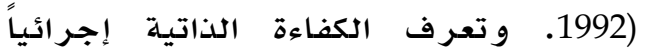

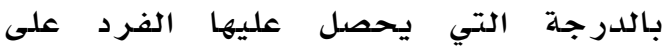
مقياس الكفاءة الذاتية العامة (GSE) و والذي يحتوي على . ال فقر ات .

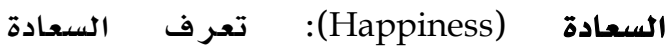

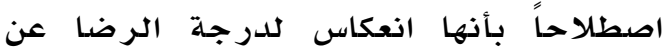
الحياة أو انعكاس لهعدلات تتكرار حلدوث الانفعالات السارة وتتضهمن الرضاه الوضا عن الحياة والاستمتاع و الشعور بالبهجة و الصحة العامـة

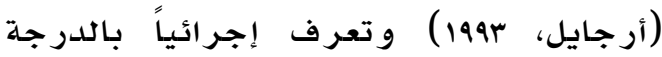

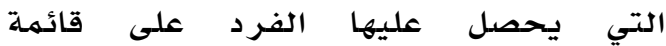
أكسفورد (Oxford) للسعادة التي تحتوي على و ب فقرة. 
للقائمهة أي من اللغة العربية إلى الإنجليزية

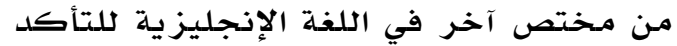

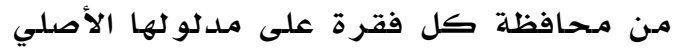

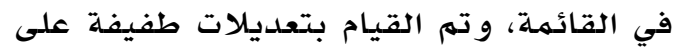
النص العربي لبعض الفقرات في ضوء هذه الها

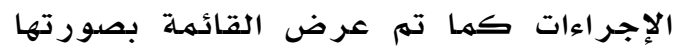
الجديدة على خمسة مختصين في علهم النفس بله التراك التربوي و القياس وطلب منههم إبداء الرأي في مدى انتماء كل فقرة إلى البعد الذي إني تقيسه و قد أجمـع المحكمون على أن الفقرات

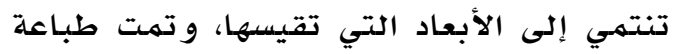

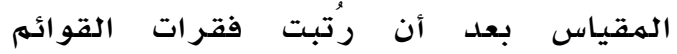

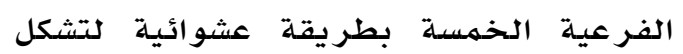
القائمـة في صدورتها النهائية

أما بالنسبة لإجر اءات صدق البناء تم تطبيق

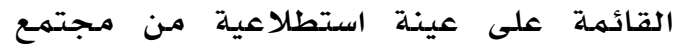

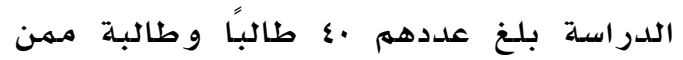
يدرسون أحد مساقات متطلبـات الجامعة لضمان تمثيل طلبة الكليات المختلفة، ووبعد ذلك تم حساب معاملات ارتباط فقرات القائمة الهصححة مـع الدرجة الفرعية، و قد الم

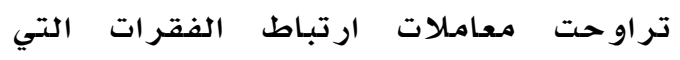
تقيس عامل المقبولية مـع البعد الذي تنتهمي

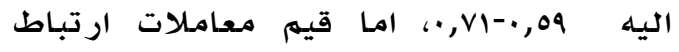

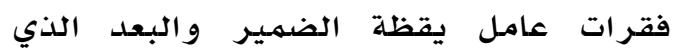

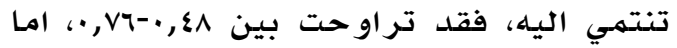

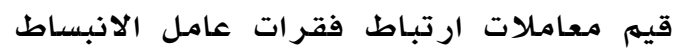
والبعد الذي تنتهي اليه، فقد تراوحت بين

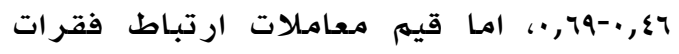

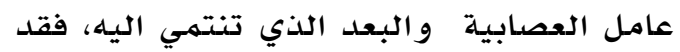
تر اوحت بين هب, •- 09, • امـا قيه معاملات ارتباط فقرات عامل الانفتاح على الخبرة و البعد الذي تنتهي اليه، فقد تراوحت بين

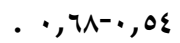

كما تم حساب ثبات الاتسـاق الداخلي

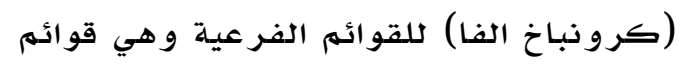

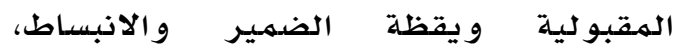
و العصابية، والانفتاح على الخبرة وكانت

\section{أولاً: قائمة العوامل الخمسة الكبرى} للشخصية (Big Five Inventory (BFI):

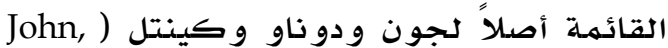
(Donahue \& Kentle, 1991 مـن ع؟ فقرة، وتتضهمن خمسة قوائم فرعية هي: يقظة الضهير، والعصابية، والانفتاح

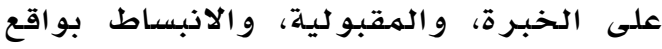

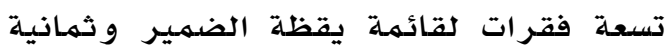

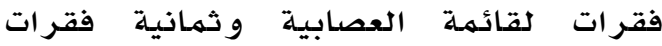

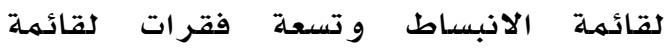
المقبولية وعشرة فقرات لقائمـة الانفتاح على الخبرة وجميع هذه المقاييس من نوع ليكرت وهي ذات تدريج خماسي تتضهمن كل منها جملة واحدة بحيث يجيب المفحوص

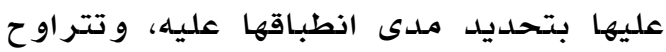
كل منها بين ا-ه كها يلي: صحيح تهاما

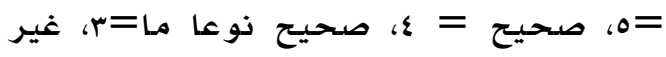
صحيح = =، غير صحيح مطلقاًً 1 و وهنالك

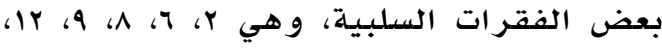

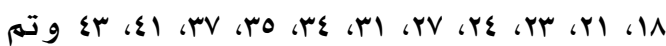
عكس درجات هذه الفقر ات.

إجراءات الصدق و الثبات الأصدي للقائمـة: القائمسة الحالية لها مؤشرات سيكو مترية جيدة في البيئة الأجنبية، فبعد تطبيقها على الى

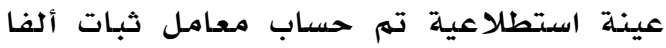
كرونباخ للانبساطية والمقبو لية ويقظة الضمير و العصابية والانفتاح على الخبرة

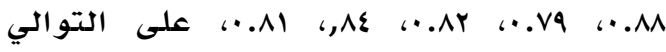
و الدرجة الكلية فكانت به.. .

أما معامل ثبات الإعادة فقد بلغت معاملات الارتباط بين التطبيق القبلي والبعدي لأبعاد

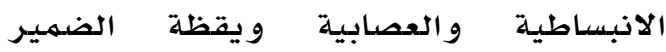

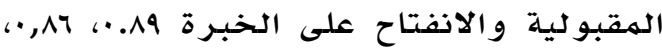

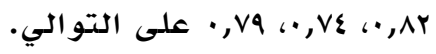
إجر اءات الصدق والثبات في الدراسلة الحالية:

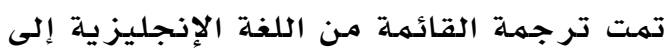

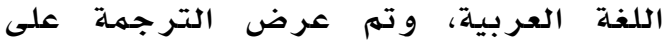
ثلاثة مختصين باللغلة الإنجليزية للتأكد من

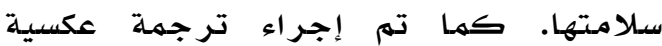


مختصين في علم النفس التربوي والقياس

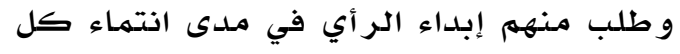

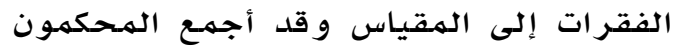

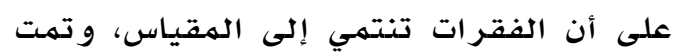

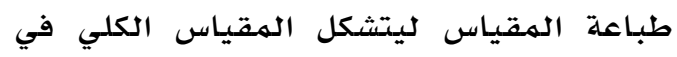
صور ته النهائية.

أما بالنسبة لإجر اءات صدق البناء تم تطبيق

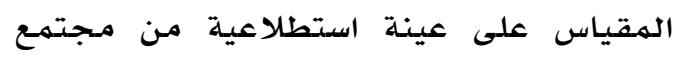

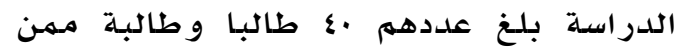
يدرسون أحد مساقات متطلبـات الجامعة لضمان تمثيل طلبة الكليات المختلفة وربعد

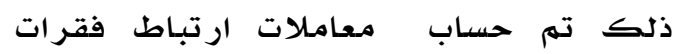

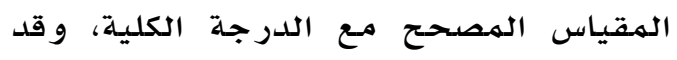
تراوحت معاملات ارتباط الفقرات مـع الأداة

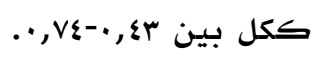

كما تم حسـاب ثبات الاتسـاق الداخلي

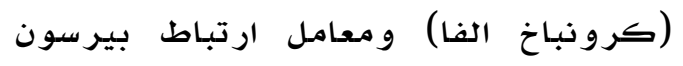
بين تقديراتهم في في الهـرتين (test-retest)

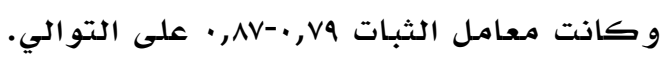

Oxford (OHI)) انياً: قائمة السعادة

(Happiness inventory

Argyle, ) القائمة أصلاً لأرجايل و مارتن و لو (martin \& Lu, 1995

Oxford Happiness أكسفورد للسعادة

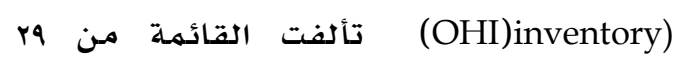
فقرة تتضمن كل منها جملة واحدة بحيث

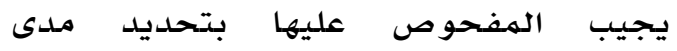
انطباقها عليه و الهقياس من نوع ليكر ت وهي

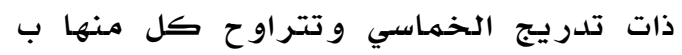
بين ا-ه كما يلي: صدحيح تماما =0، صحيح ع= غير صحيح مطلقاً= 1 وهنالك

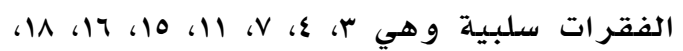
19، ·r و تم عكس درجات هذه الفقر ات. إجراءات الصدق والثبات الأصلي للقائمهة:

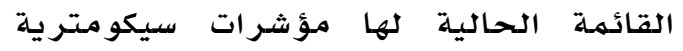

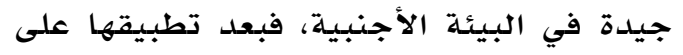

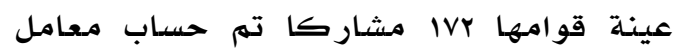

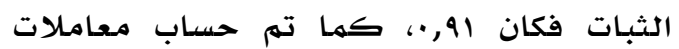

$$
\text { ععاملات ثباتها }
$$

مeneral Self-) مقياس الكفاءة الذاتية العامة :(Efficacy Scale(GSE)

و وضعه أصدلا" ) Schwarzer \& Jerusalem, ) 1995) يتألف المقياس من (.1) فقرة تتضمن

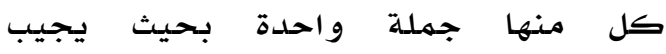
المفحوص عليها بتحديد مدى انطباقها عليه و المقياس من نوع ليكرت وهي ذات تدريج

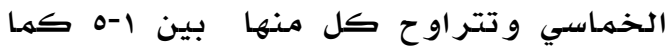

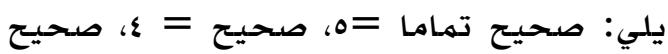

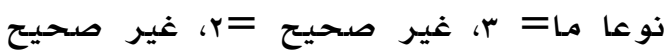

$$
\text { مطلقاً = مو } 1 .
$$

إجراءات الصدق والثبات الأصلي للمقياس:

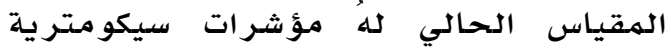
جيدة في البيئة الأجنبية فبعد تطبيقه على مبلى

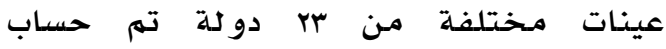

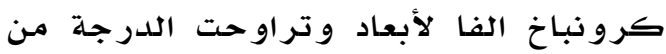

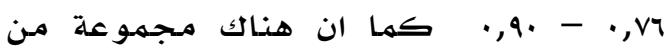

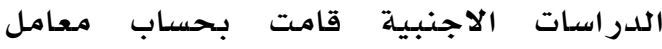

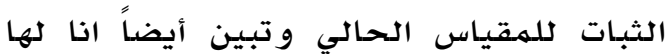

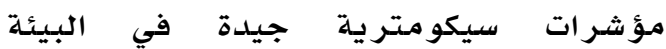
الأجنبية، ففي دراسـة Luszczynska, Scholz (Scholz, و ودراسة (\& Schwarzer, 2005) Dona, Sud \& Schwarzer, 2002)

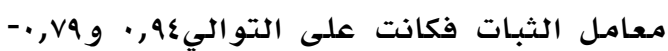
$\therefore, \wedge \vee$

إجراءات الصدق والثبات في الدر اسـة الحالية: تمت ترجمة الهقياس مـن اللغة الانجليزية

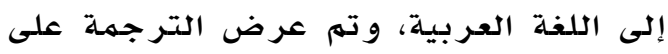

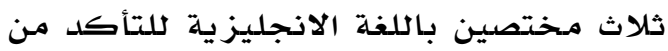

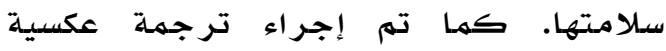

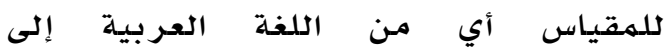

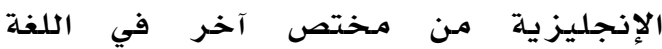
الإنجليزية للتأكد من محافظة كل كل فقرة على مدلو لها الأصلي في الهقياس وتهم القيام

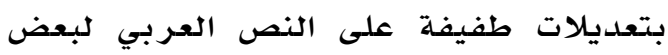

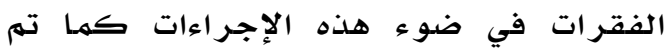
عرض الهقياس بصورته الجديدة على خمسـة 
وطالبـة مهـن يلدرسون أحد مساقات متطلبـات

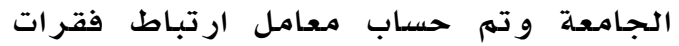

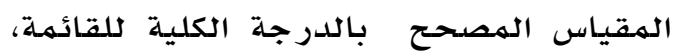

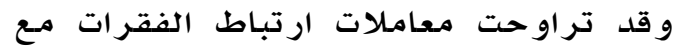
الأداة ككل بين سץ, •- بآ,•، كما تم حساب

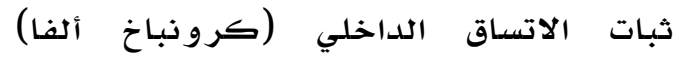

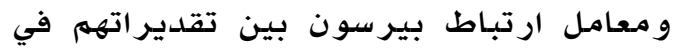

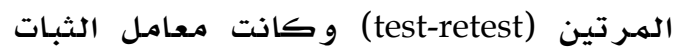

$$
\text { ه, ••-91, ••على التواني. }
$$

$$
\text { متغير ات الدراسة }
$$

تضمنت الدراسة المتغيرات المستقلة التالية

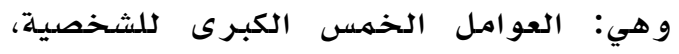
الكفاءة الذاتية الكية

المتغير ات التابعة: السعادة.

\section{نتائج الدراسة ومناقشتها}

سيتهم عرض النتائج وفق أسئلتهاعلى النحو الآتى: لئم

السؤال الأول: هل يتفق النموذج النظري

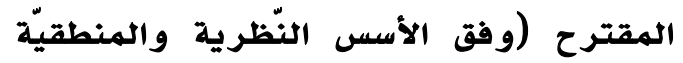

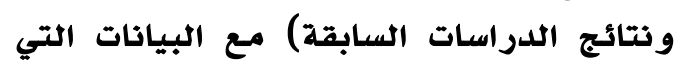

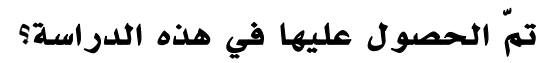

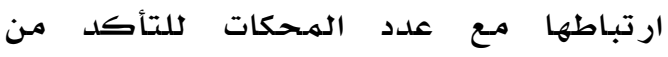

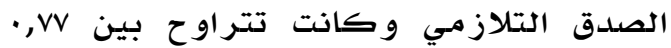

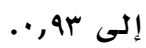

إجراءات الصدق و الثبات للدراسة الحالية:

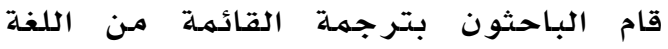

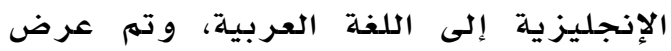

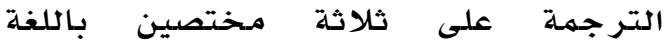

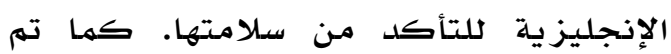

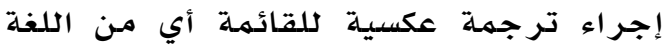
العربية إلى اللغة الإنجليزية من من مختصه

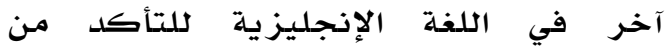
محافظة كل فقرة على مدلولها لها الأصلي في

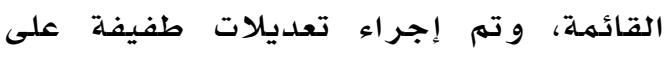
النص العربي لبعض الفقرات في ضوء هذه الاهرا

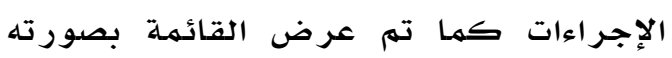
الجديدة على خمسـة مختصين في علم النفس

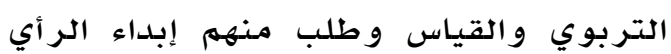

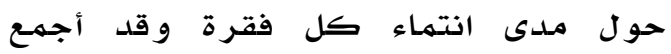

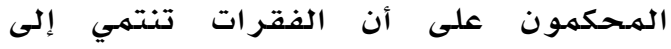
المقياس وتمت طباعة القائمهة.

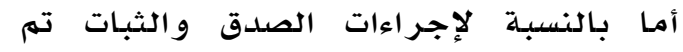

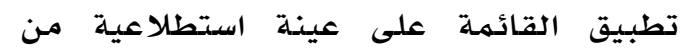

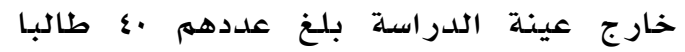

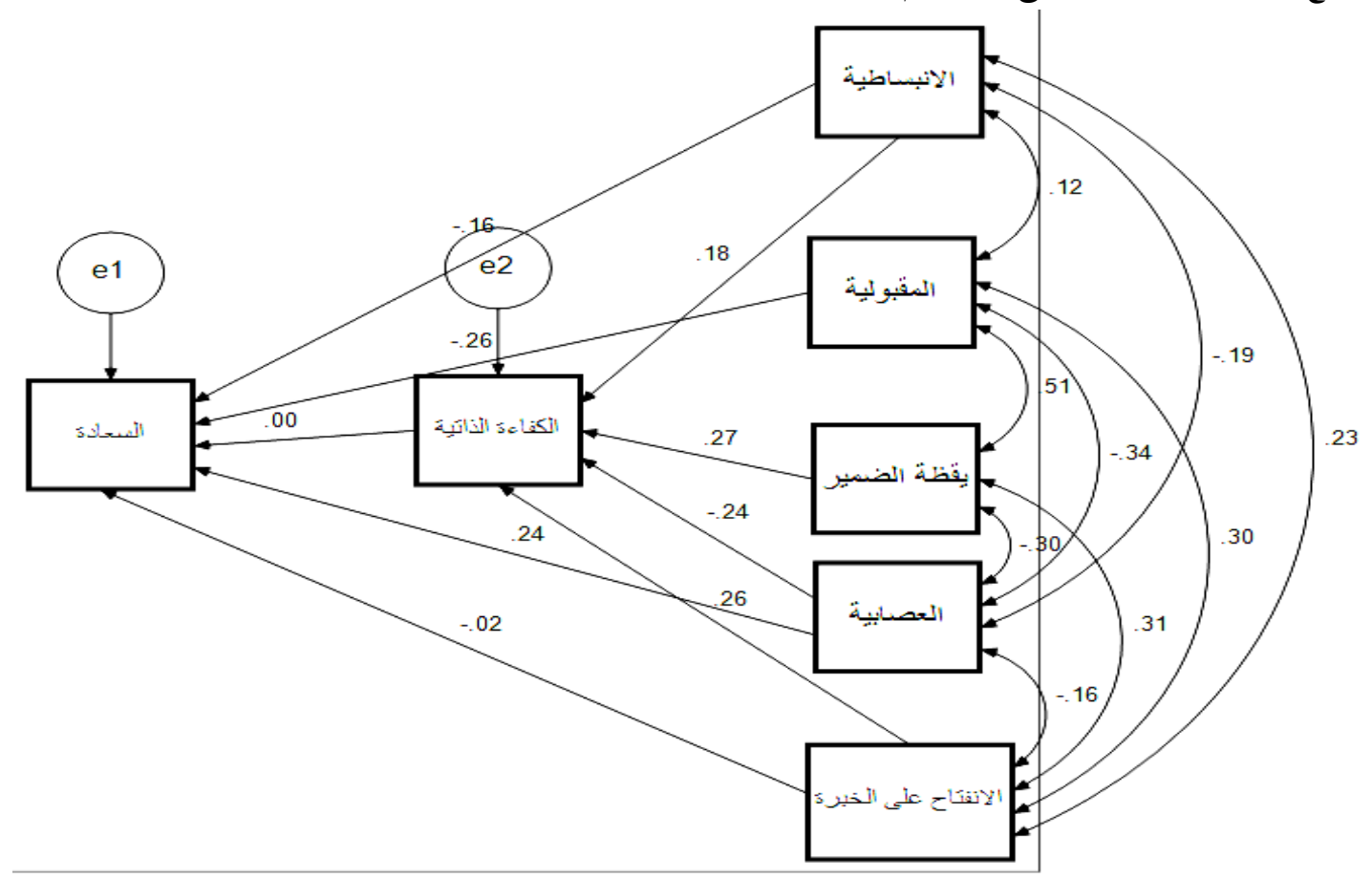

شكل 1: قيم معاملات المسار للنموذج السببي الافتراضي 


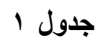

قيم معاملات الانحدار للمسارات السبيية بالقيم المعيارية وغير المعيارية

\begin{tabular}{|c|c|c|c|c|}
\hline القيم الحرجة & $\begin{array}{l}\text { الخطأ المعياري } \\
\text { S.E }\end{array}$ & بالقيم غير المعيارية الانحدار & معامل الانحدار بالقيم & المسار السببي \\
\hline$* \varepsilon, 10$ & $\cdot, 0$ & $\cdot, r$ & $\cdot, 11$ & الانبساطية --> الكفاءة الذاتية \\
\hline$*\rceil, \cdot r$ & $\cdot, \cdot 0$ & $\cdot, 11$ & $\cdot, Y V$ & يقظة الضمير --> الكفاءة الذاتية \\
\hline$*_{-} 0, \Gamma \wedge$ & $\cdot, \cdot 4$ & $-\cdot, r \cdot$ & $-\cdot, r \leqslant$ & العصابية --> الكفاءة الذاتية \\
\hline$* 0,9$. & $\cdot, \cdot 0$ & r & $\cdot, Y 7$ & الانفتاح على الخبرة --> الكفاءة الذاتية \\
\hline$-\cdot, \cdot 7$ & $\cdot, \cdot r$ & $-\cdot, \cdot 1$ & $-\cdot, \cdot 1$ & الكفاءة الذانية --> السعادة \\
\hline$*_{-},, r \cdot$ & $\cdot, \cdot r$ & $-\cdot, \cdot \wedge$ & $-\cdot, 17$ & الانبساطية --> السعادة \\
\hline$*_{-} 0,1 r$ & $\cdot, \cdot r$ & $-\cdot, 1 T$ & $-\cdot, r 6$ & المقبولية --> السعادة \\
\hline$* \varepsilon, \mathrm{V}$ & $\cdot, \cdot r$ & $\cdot, \cdot 9$ & $\cdot, r \leq$ & العصابية --> السعادة \\
\hline$-\cdot, \Gamma_{\Lambda}$ & $\cdot, \cdot r$ & $-\cdot, 1 \cdot$ & $-\cdot, r$ & الانفتاح على الخبرة --> السعادة \\
\hline
\end{tabular}

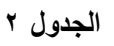

حجم الأثر المباشر وغير المباشر والأثر الإجمالي لمتغيرات النموذج الافتراضي (بالقيم المعيارية)

\begin{tabular}{|c|c|c|}
\hline الأثر & 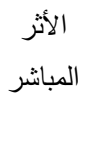 & 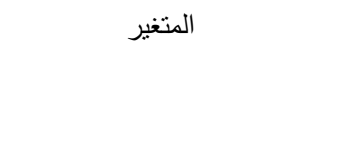 \\
\hline$\cdot, \cdot$ & $\cdot, 11$ & الانبساطية ---> الكفاءة الذاتية \\
\hline$\cdot, \cdots$ &,$\cdots$ & المقبولية ---> الكفاءة الذاتية \\
\hline$\cdot, \cdot$ & $\cdot, r V$ & يقظة الضمير ---> الكفاءة الذاتية \\
\hline,$\cdots$ & $-\cdot, r \leq$ & العصابية ---> الكفاءة الذاتية \\
\hline$\cdot, \cdot$ & $\cdot, r 4$ & الأنية النتاح على الخبرة ---> الكفاءة \\
\hline,$\cdots$ & $-\cdot, \cdot 1$ & الكفاءة الذاتية ---> السعادة \\
\hline$\cdot, \cdots$ & $-\cdot, 17$ & الانبساطية ---> السعادة \\
\hline$\cdot, \cdots$ & $-\cdot . r$ & المقبولية --->> السعادة \\
\hline$\cdot, \cdots r$ & $\cdot, \cdots$ & يقظة الضمير ---> السعادة \\
\hline$\cdot, \cdots r$ & $\cdot, r \varepsilon$ & العصابية ---> السعادة \\
\hline$\cdot, \cdot$ & $-\cdot, \cdot r$ & الانفتاح على الخبرة ---> السعادة \\
\hline
\end{tabular}

يتضح من جلدول ب بأن المسسارات غير

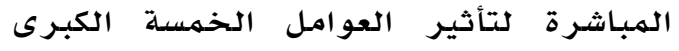

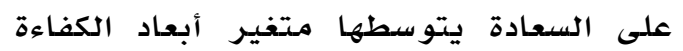

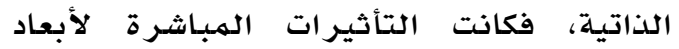
العوامل الانبساطية والهقبولية والعصدابية

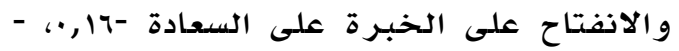

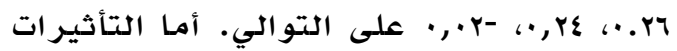

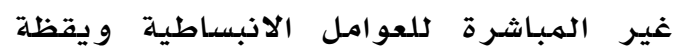
الضمير و العصابية والانفتاح على الخبرة

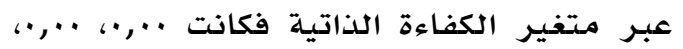

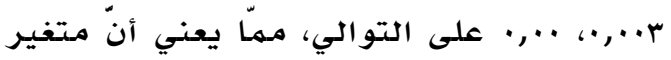

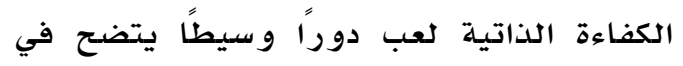

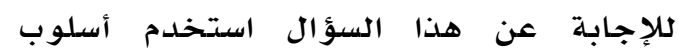
تحليل الهسار (Path Analysis)، واختبـار

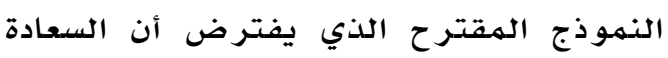

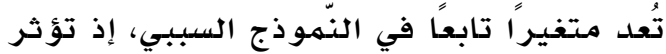

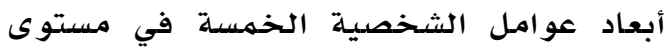

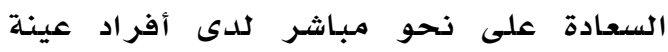

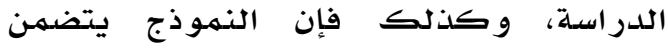

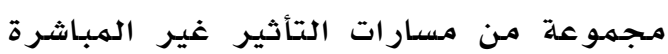

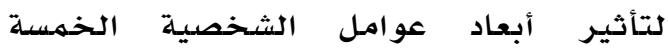

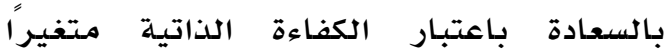

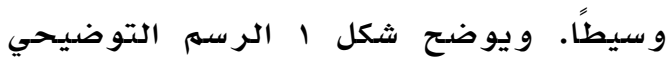
ل كلنهموذج

كما تم اختبار العلاقات المباشرة بين الهتغير ات في النموذج الافتر اضي رهما

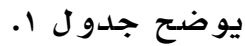
يظهر من خلال قيه الدلالة الإحصائية الواردة في جدول ا أن جميع معاملات

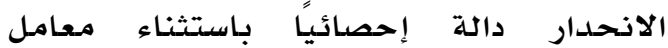

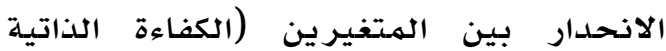

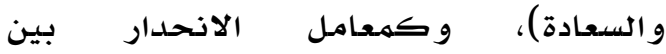
المتغيرين (الانفتاح على الخبرة و السعادة)، وادة)

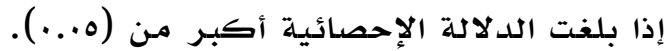

كما تمَّ استخر اج قيم الأثر المباشر ( Direct )

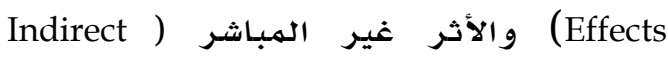
(Effects الافتر اضي. وقد كانت كما هو موضتح في

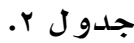


كما تَمّ استخراج قيمـة اختبـار مربع كاي

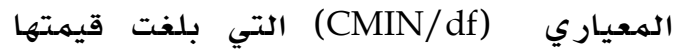
قو r,VVr قبول الفرضية الصفرية التي تنص على عدم و جود فروق ذات دلالة إحصائية بين النموذ جري

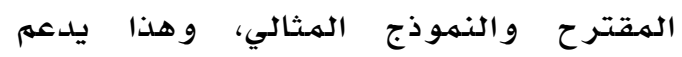

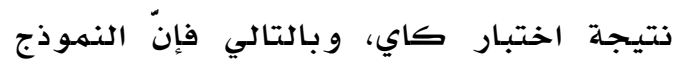
يفسرّ العلاقةات التي تم اقتر احها وهو هو يعبر

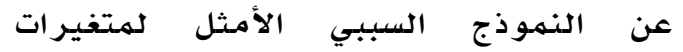

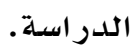

\section{مناقشة النتائج}

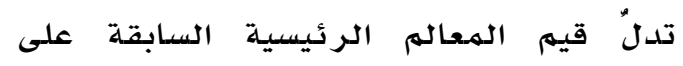

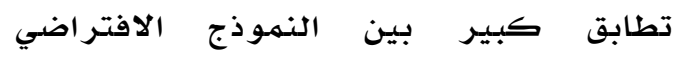
وبيانات الدراسـة، ذلك أن مؤشرات المطابقة

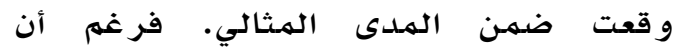

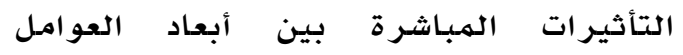

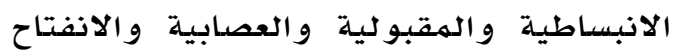

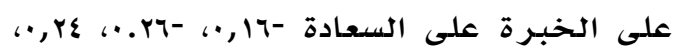
-ץ.,

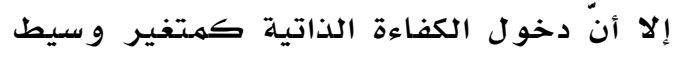

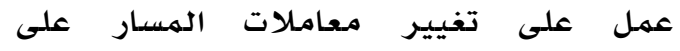

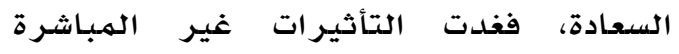

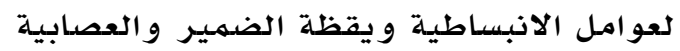
والانفتاح على الخبرة عبر متغير السعادة

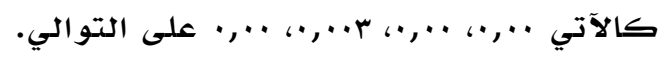
يمكن تفسير هذه النتيجة في ضدو النظرية

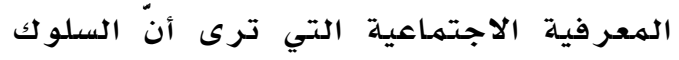

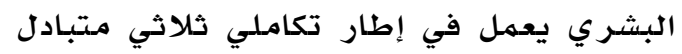

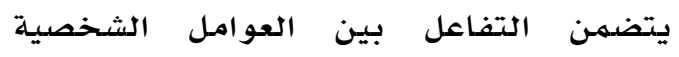

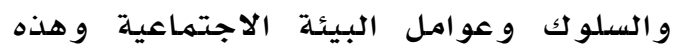
التأثيرات تظهر على شكل وفاءة ذاتيلة باعتبارها عامل أساسي للشخصية لأنها تستند إلى معتقدات تقييمية عن الحياة و تأثيرها

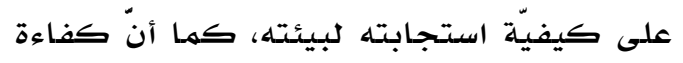

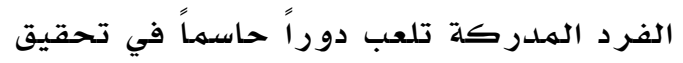
السعادة؛ فرغم تمتع الأفر اد بعوامل دول شخصدية

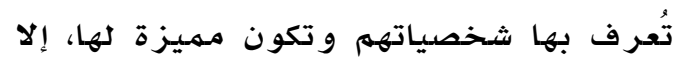

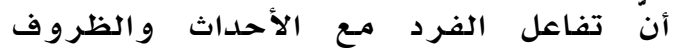
البيئية لا يتم بمعزل بمل عن تقييم الفرد الاحد

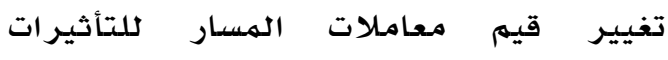
الهباشرة لهذه العوامل، فيلاحظ أن التأثير

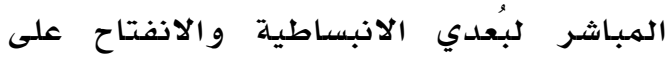
الخبرة قد أثر فيه متغير الكفاءة الذاتية بشكل غير مباشر حيث تلاشى هذا التأثير

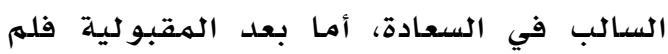

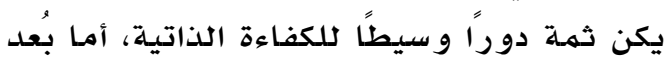

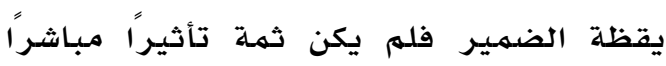
على السعادة، إنما تأثير غير مباشر لهالب،

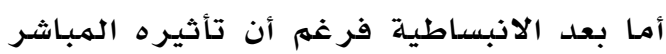

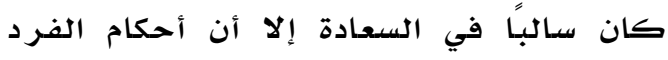

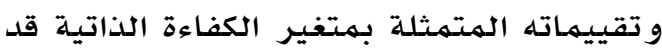
جعلت تأثير هذا العامل على السعادة موجيًا.

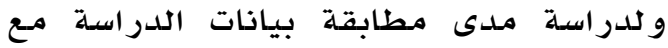

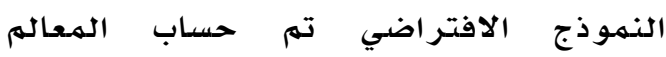
الرئيسة للمطابقة، و قد بلغت هذه القيهم كما هو موضتح في جدو ل بر: جدول r مؤشرات المطابقة للنموذج الافتراضي المقترح

\begin{tabular}{|c|c|c|}
\hline القيمة & حدود الثقة & المؤشر \\
\hline$\cdots 7$ & $\cdots \wedge-$ & $\begin{array}{r}\text { RMSEA } \\
\text { (التزبيعي لمتوسط مربعات الاقتراب) } \\
\text { الجذرب }\end{array}$ \\
\hline. .99 & $1-.9$ & 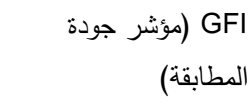 \\
\hline. .99 & $1-. .9$ & $\begin{array}{r}\text { NFI } \\
\text { (مؤشر المطابقي) }\end{array}$ \\
\hline. .99 & $1-.9$ & $\begin{array}{r}\text { المقارن) CFI } \\
\text { (مؤشر المطابقة }\end{array}$ \\
\hline .94 & $1-\cdot .9$ & TLI (مؤشر ناكر_لويس) \\
\hline$\because 9 \leq$ & $1-.9$. & 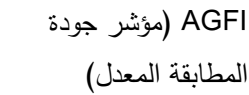 \\
\hline
\end{tabular}

كَما تمَّ استخراج قيمة اختبـار مربع كاي

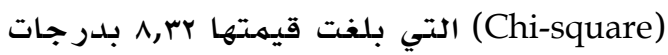

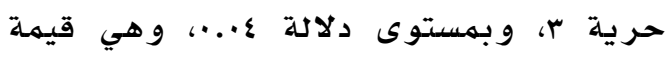

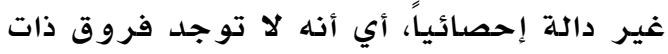

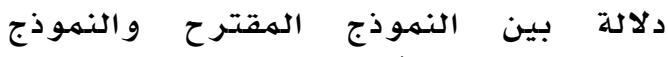

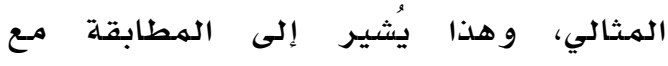

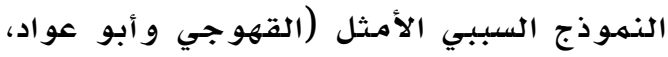
. $(r \cdot 11$ 
و تختلف هذه النتيجة كذلك مع دراسة ديبا و آخرون (Deepa et al., 2014) التي دهوه توصلت إلى وجود علاقة إيجابية بين الكفاءة

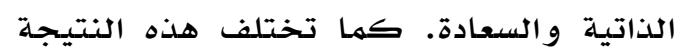

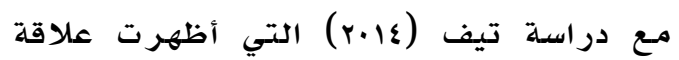

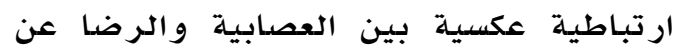

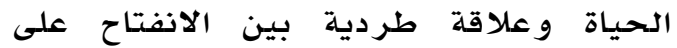

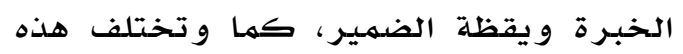

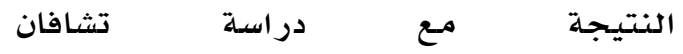
و بادجوجار (Chavan \& Badgujar, 2016 (C) التي

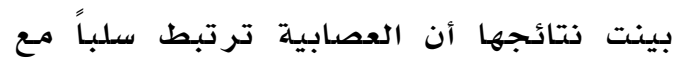

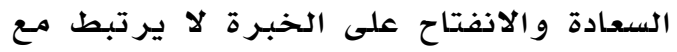
السعادة.

التوصيات

ا. عقد ورش عمل في الجـامعة لتبصير

الطلبـة بالعوامل الكبرى الشخصية

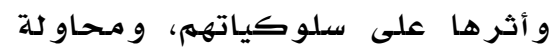

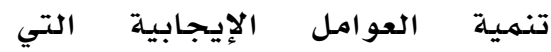

يفتقر ون إليها.

r. إضافة مادة في الجامعة تتعلّق بعله

النفس الايجابي وتطوير الذات.

r. إجراء دراسـات تَعتمدُ أُسلوب تَحَليل

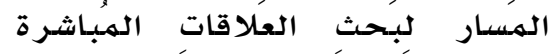

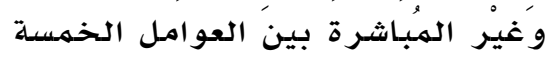

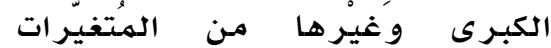

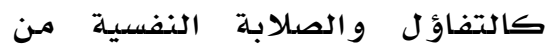

جهة و السّعادة من جهة أخرى.

المراجع

\section{References}

أبو هاشهم، محمد (.1.r). النموذج البنائي

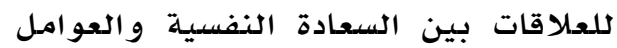
الخهسة الكبرى للشخصية وتقدير الذات

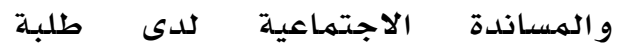

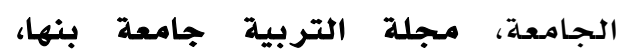
ro.-run،(1) r r

أرجايل، مايكل. (1994). سيكولوجية السعادة.

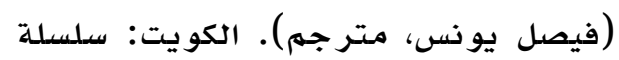

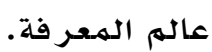

لكفاءته الذاتية لتلك الأحداث و الظروف من حيث ما يستطيع إنجازه و ما لا لأيستطيع؛

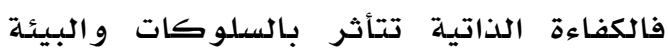
المحيطة إذ عندما يكون قادر على التعامل

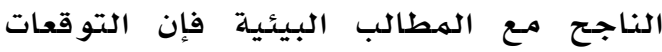
تلعب دور مهماً في تحقيق التوافق النفسي، النئيل أما في حال اختالال هذه التوقعات تؤدي إلى لى لى دولى

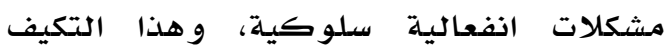

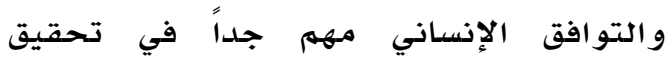
السعادة.

كما يمكن أن تفسر هذه النتيجة في ضدو ما تقوم الكفاءة الذاتية من تعزيز الشعور

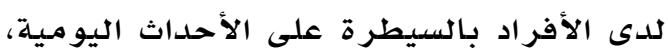

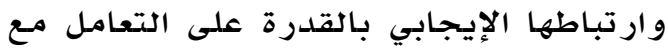

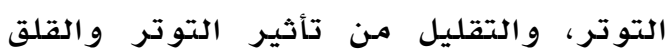

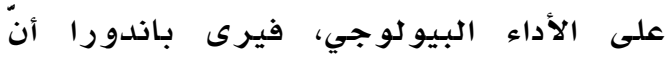

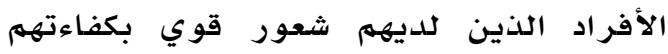

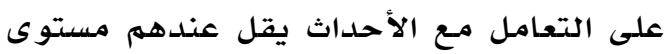
التوتر والاكتئاب أثناء مجابهة الصعوبات

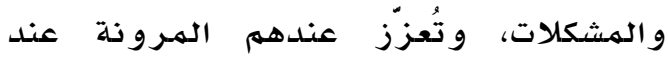

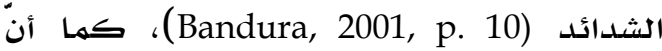

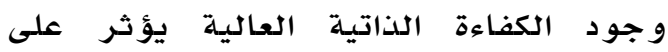

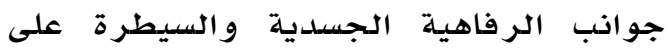

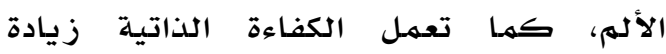
الاندورفين الذي يعتبر من مسكنات الألهم الطبيعية التي يفرزها الجسهم، مـما يجعله

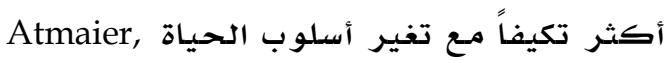
Russell, Kao, Lehmann \& Weinstein, .(1993)

و تتفق هذه النتيجة هزئيًا مع دراسـة سترو بل و آخرون (Strobel et al., 2011) التي دئي بيّنت أن الكفاءة الذاتية يمكن أنْ تأخذ دورًا

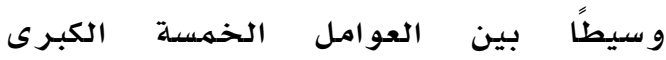
للشخصية (العصابية والانبسيساط و ويقظة الضمير و الانفتاح على الخبرة) والسعادة. وتختلف هذه النتيجة هزئيا أبو هاشم

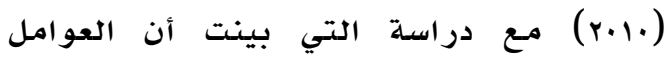

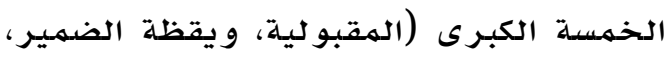

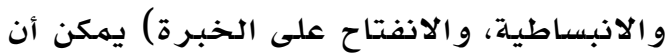
تؤثر بشكل إيجابي في السعادة. 
Altmaier, E. M., Russell, D. W., Kao, C. F., Lehmann, T. R., \& Weinstein, J. N. (1993). Role of self-efficacy in rehabilitation outcomes among chronic low back pain patients. Journal of Counseling Psychology, 40, 335-339.

Argyle, M., Martin, M., \& Lu, L. (1995) Testing for stress and happiness: The role of social and cognitive factors. In.

Bandura, A. (1995). Exercise of personal and collective efficacy in changing societies. In A. Bandura (Ed.), Selfefficacy in changing societies (pp. 1-45). New York: Cambridge University Press.

Bandura, A. (2001). Social cognitive theory: An agentic perspective. Annual Review of Psychology, 52, 1-26.

Barber, E. (2010). An Examination of Happiness and Its Relationship to Community College Coping Strategies and Academic Performance, Unpublished Doctoral Dissertation, Morgan State University.

Csikszentmihalyi, M., \& Hunter, J. (2003). Happiness in Everyday Life: the Uses of Experience Sampling. Journal of Happiness Studies, 4, 185-199.

Dale, L., \& Harrison, D. (2017). How the Big Five personality traits in CPSQ increase its potential to predict academic and work out comes. Cambridge Assessment Admissions Testing.

Deepa L. H., \& Suneetha, J. (2014). SelfEfficacy and Happiness in Youth.. Journal of the Indian Academy of Applied Psychology,40(1), 70-73.

Diener, E., \& Suh, E. (2000). Cultue and Subjective Well-Being. Massachusetts: MIT press.

Dogan, T. \& Cotok, N. (2011) Adaptation of the Short Form of the Oxford Happiness Questionnaire into Turkish: A Validity and Reliability Study Turkish Psychological Counseling and Guidance Journal, 4 (36), 165-172.

Ekermans, G., \& Steyn, R. (2016). Optimism, Self-Efficacy and Meaningfulness: A Structural Model of SubjectiveWell-Being at Work. Management Dynamics, 24(4), 34-51.

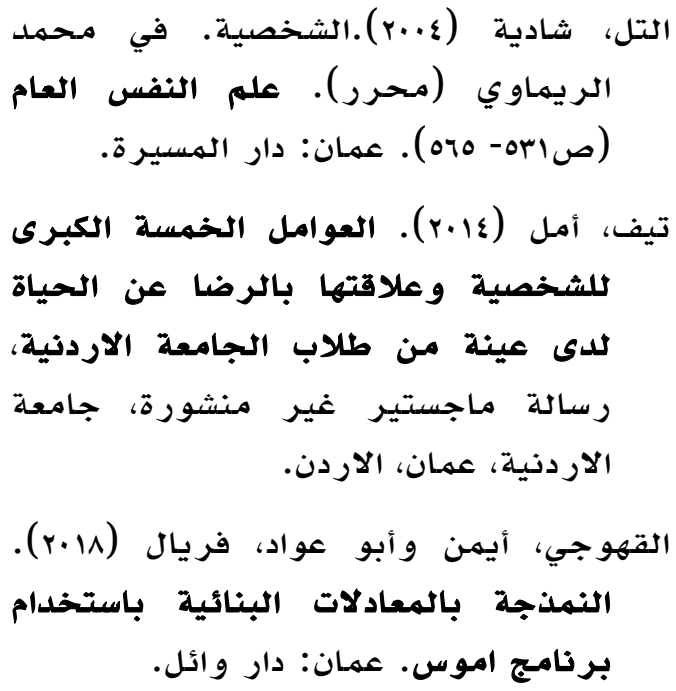


Emine, G., \& SATICI, S. (2015).BIG Five And Subjective Happiness. Education Science and Psychology,35(3),10-15.

Erozkan, A., Dogan, A., \& Adiguzel, A. (2016).Self-efficacy, Self-esteem, and Subjective Happiness of Teacher Candidates at the Pedagogical Formation Certificate Program. Journal of Education and Training Studies,4(8),7282.

Eysenck, H. (2013). The Structure of Human Personality. New York: Routledge.

Gosling, S., \& Rentfrow, P., \& Jr, W. (2003). A very Brief Measure of the Big-Five Personality Domains. Journal of Research in Personality, 37, 504-528.

Graziano, W., \& Tobin, R. (2009). Agreeableness. In M. R. Leary \& R. H. Hoyle (Eds.), Handbook of individual differences in social behavior (pp. 46-61). New York, NY: Guilford.

John, O., \& Srivastava, S. (1999). The big five trait taxonomy: History, measurement, and theoretical perspectives. In L. A. Pervin \& O. P. John (Eds.), Handbook of Personality: Theory and Research (2nd ed., pp. 102139). New York: Guilford Press.

John, O., Donahue, E., \& Kentle, R. (1991). The Big Five Inventory - Versions $4 a$ and 54. Berkeley, CA: University of California, Berkeley, Institute of Personality and Social Research.

Jones, K. (2011). Teacher Self-Efficacy Beliefs Related to Chronic Disruptive Behavior. Unpublished Doctoral Dissertation, Indiana State University.

Karademas, E., Kafetsios. K., \& Sideridis. G. (2007). Optimism, Self - Efficacy and Information Processing of Threat - and Well - Being - Related Stimuli. Stress and Health, 23, 285-294.

Khan, R. (2009). The Perception of Happiness: Role of Age and Culture. Unpublished Doctoral Dissertation, Kean University.

Langevin, E.(2013). Undergraduate Student Happiness and Academic Performance: A Correlation Study. Unpublished Doctoral Dissertation, University Of Phoenix.
Larsen, R., \& Buss, D. (2005). Personality Psychology: Domains of Knowledge about Human Nature (2nd Ed.). New York: McGraw Hill.

Li, F., McAuley, E., Harmer, P., Duncan, T., \&Chaumeton, N. (2001). Tai Chi enhances self-efficacy and exercise behavior in older adults. Journal of Aging and Physical Activity, 9, 161-171.

Lu, L .(2001).Understanding Happiness: A look into the Chinese Folk Psychology. Journal of Happiness Studies,2, 407-432.

Luszczynska, A., Scholz, U., \&Schwarzer, R. (2005). The General Self-Efficacy Scale: Multicultural Validation Studies. The Journal of Psychology, 139(5), 439457.

Maddux, J .(1995). Self-Efficacy, Adaptation, and Adjustment: Theories, Research, and Application. New York: Springer.

McCrae, R., \& Costa, T. (1997). Personality trait structure as a human universal. American Psychologist, 52(5), 509-516.

McCrae, R., \& John, O. (1992). An introduction to the five-factor model and its applications. Journa1 of Personality, 60, 175-2 15.

Mishra, K. (2013). Optimism and WellBeing. Social Science International, 29(87), 75-87.

Nistor, A .(2011). Developments on the Happiness Issues: a Review of the Research on Subjective Well being and Flow. Scientific Journal Studies, 3 (4), 58 66.

Pacheco. B., \&Kamble, S. (2016). Role of Optimism in the Well-Being of Undergraduate in Goa. Indian Journal of Health and Wellbeing. 7(4), 419-422.

Padhy, M., Chelli, K., \& Padiri, R. (2015). Optimism and Psychological WellBeing of Police Officers With Different Work Experiences. SAGE Open, 1-7.

Phan, H., Ngu, B., \&Alrashidi, O. (2016). Role of Student Well-Being: A StudyUsing Structural Equation Modeling. Psychological Reports, 119(1), 77-105.

Richard, L .(2005). Happiness; Lessons from A New Science. NY: Penguin press. 
Ryan, R., \&Deci, E .(2001). On Happiness and Human Potentials: A review of Research on Hedonic and Eudaemonic Well-Being. Annual Review of Psychology, 52, 141-166.

Ryckman, R. (2008). Theories of Personality. Belmont: Thompson Wadsworth.

Salama-Younes, M. (2011). Positive mental health, subjective vitality and satisfaction with life for French physical education students. World Journalof Sport Sciences, 4(2), 90-97.

Saurabh, C.,\& Badgujar, C .(2016). Big Five Personality Factors and Happiness. European Academic Research,3 (1), 520530

Scheier, M., Carver, C., \& Bridges, M. (1994). Distinguishing optimism from neuroticism (and trait anxiety, selfmastery, and self-esteem): A reevaluation of the Life Orientation Test. Journal of Personality and Social Psychology, 67, 1063-1078.

Scholz, U., Dona, B., Sud, S., \& Schwarzer, R. (2002). Is General Self-Efficacy a Universal Construct. European Journal of Psychological Assessment, 18(3), 242-251.

Schultz, D., \& Schultz, S. (2009). Theories of Personality . Belmont: Wadsworth.

Schunk, D., \& Mullen. C.(2012). SelfEfficacy as An Engaged Learner, In S. L. Christenson, A. Reschly, \& C. Wylie (Eds.), Handbook of Research on Student Engagement (Chpt. 2, Pp. 21-44). New York: Springer.

Schwarzer, R. (Ed.) (1992). Self-efficacy: Thought control of action. Washington, DC: Hemisphere.

Schwarzer, R., \& Jerusalem, M. (1995). Generalized Self-Efficacy Scale. In J. Weinman, S. Wright, \& M. Johnston, Measures In Health Psychology: A User's Portfolio. Causal And Control Beliefs (Pp. 35-37). Windsor, UK: NFER-NELSON.

Seifert, K., \& Sutton, R .(2009). Educational Psychology. Zurich: The Saylor Foundation.

Seligman, M.(2004). Can Happiness be Taught. Daedalus, 133(2), 80-87.
Sezgin, S. \& Erdogan, O. (2015). Academic Optimism, Hope and Zest for Work as Predictors of Teacher Self-efficacy and Perceived Success. Educational Sciences: Theory \& Practice. 15(1), 7-19.

Siddiqui, S. (2015). Impact of Self-Efficacy on Psychological Well-Being among Undergraduate Students. The International Journal of Indian Psychology,2(3), 5-16.

Strobel, M., Tumasjan. A. \& Sporrle. (2011). Personality and Social Psychology Be Yourself, Believe in Yourself, and Be Happy: Self-Efficacy as A Mediator Between Personality Factors and Subjective Well-Being. Scandinavian Journal of Psychology, 52, 43-48.

Vilhena, E., Ribeiro, J., Silva, I., Pedro, L, Meneses, R, Cardoso, H., Silva, A. \&Mendonça, D. (2014). Optimism on Quality of Life in Portuguese Chronic Patients: Moderator/Mediator?. Rev Assoc Med Bras. 60(4),373-380.

World Health Organization (1997). Program on Mental Health. WHOQOL: Measuring Quality of Life. Division of Mental Health and Prevention of Substance Abuse .World Health Organization.

Retrieved1.5.2017fromhttp://www.wh o.int/mental_health/media/68.pdf.

Zhang, R. (2016). Positive Affect and SelfEfficacy as Mediators Between Personality and Life Satisfaction in Chinese College Freshmen. Happiness Stud. 17, 2007-2021.

Zimmerman, B. (2000). Self-Efficacy: An Essential Motive to Learn. Contemporary Educational Psychology, 25, 82-91. 